\title{
El toro orientalizante de Porcuna (Jaén)
}

\author{
The Orientalizing Bull from Porcuna (Jaén)
}

\author{
Teresa Chapa Brunet*, Luis Emilio Vallejo** \\ *Departamento de Prehistoria. Universidad Complutense. 28040 Madrid. tchapa@ghis.ucm.es \\ **Director del Museo y Conjuntos Arqueológicos de Porcuna. 23790 Porcuna (Jaén). porcunacultura@promojaen.es
}

Recibido: 26-06-2011

Aceptado: $30-01-2012$

\section{RESUMEN}

La escultura en piedra ha sido considerada como un elemento diagnóstico de la Cultura Ibérica. Sin embargo, recientes hallazgos y revisiones de piezas permiten apreciar que también se recurrió a estas manifestaciones iconográficas en épocas pre-ibéricas. Se presenta como ejemplo el toro echado de Porcuna como evidencia de la escultura orientalizante en piedra en el área central de Andalucía, proponiéndose una cronología de fines del s. VII o inicios del s. VI a.C. Al análisis iconográfico tradicional se añade una primera valoración como obra de un taller escultórico, analizando los complejos trabajos de diseño y manufactura aplicados en esta obra. Uno de los aspectos más interesantes es la presencia de elementos accesorios, probablemente de materiales valiosos. Proponemos asociar este toro a un lugar de culto situado en la entrada de la antigua población de Porcuna.

Palabras Clave: Península Ibérica. Periodo Orientalizante. Escultura en piedra. Toro echado. Talleres de escultura. Apliques metálicos.

\begin{abstract}
The stone sculpture has been considered as a diagnostic feature of the Iberian Culture. Nevertheless, recent findings and re-examination of old ones suggest that it was already employed in pre-Iberian times. The kneeling bull from Porcuna is presented here as an evidence of the orientalizing stone sculpture in Central Andalusia, and a dating around the end of the $7^{\text {th }}$ or the beginning of the $6^{\text {th }}$ century BC is proposed. In addition to the iconographic study, the sculpture is also discussed as a workshop product, analyzing the complex skills of design and manufacture displayed, from the stone cutter to the master sculptor. One of the most interesting aspects is the presence of applied elements, probably made of valuable materials. It is also proposed that the bull was placed on a cult place at the entrance of the ancient town of Porcuna.
\end{abstract}

KEY words: Iberian Peninsula. Orientalizing period. Stone Sculpture. Kneeling Bull. Sculpture Workshops. Metal Attachments.

Sumario 1. Introducción. 2. Descripción de la pieza. 3. Diseño y proceso de talla. 4. Adornos florales y elementos accesorios. 5. Contexto cultural e iconográfico. 6. Hipótesis sobre el monumento al que correspondería la escultura. 7. Conclusiones. 8. Agradecimientos. Referencias bibliográficas. 


\section{Introducción}

El toro echado, que por sus dimensiones en relación a los grandes novillos del Cerrillo Blanco suele ser denominado como "torito de Porcuna", ha sido justamente reconocido como una obra exquisita de la escultura ibérica. Las publicaciones disponibles sobre esta pieza apenas ofrecen datos sobre las circunstancias de su hallazgo y su traslado a Jaén, lo que hace pertinente ampliar esta información con las noticias que hemos podido recopilar hasta el momento ${ }^{1}$.

La escultura apareció en 1946, en el "Haza de Napoleón", frente al actual cuartel de la Guardia Civil, cuando se procedió a desmontar un terraplén para abrir y mejorar el camino desde Porcuna hacia Alharilla y Arjona. En este lugar había una escombrera, y allí se recuperó el toro, aunque se desconoce si formaba parte de los vertidos realizados por las viviendas del entorno o si -como parece más probable- apareció en las remociones asociadas al desmonte. La obra se realizó bajo la dirección de Ramón Pajares Pardo, y el toro fue llevado directamente a la sala de bóvedas situada en los bajos del Ayuntamiento, donde se acumulaban los objetos arqueológicos e históricos procedentes de donaciones o de encuentros fortuitos. Esta zona ha sido muy rica en restos, aunque siempre faltos de contexto. Entre ellos cabe citar unos capiteles con motivos trenzados, de época ibérica plena o tardía, asociados seguramente a un edificio de culto. Estas piezas se conservan en Porcuna y permanecen inéditas.

A principios de la década de 1950, el alcalde quiso obsequiar a Pajares Pardo con algunos de los restos conservados en estas salas, en reconocimiento a su importante labor como arquitecto de "Regiones Devastadas" en Porcuna, y éste trasladó a su casa el toro. De esta época es la primera imagen que conservamos, realizada por el fotógrafo César Cruz (Fig. 1). Algo más tarde la pieza fue cedida por el propio Pajares Pardo al Instituto de Estudios Giennenses, de donde pasó al Museo de Jaén en $1973^{2}$, siendo su número de inventario CE/DA00818.

Los diversos hallazgos realizados, tanto en el casco urbano de Porcuna como en su término municipal, nos indican que en este lugar existió un centro de producción de esculturas que perduró largo tiempo. Además de la figura que estudiamos, en el vecino Cerrillo Blanco, situado a menos de $2 \mathrm{~km}$ de distancia en dirección norte, se localizó el conjunto más importante de esculturas ibéricas del s. V a.C. conocido hasta la fecha (González Navarrete 1987; Negueruela 1990). El Museo Municipal de Porcuna alberga igualmente, junto a otros restos esculpidos, el cuerpo exento de una leona ibérica, donado por D. Juan Antonio Millán Casado, procedente de la
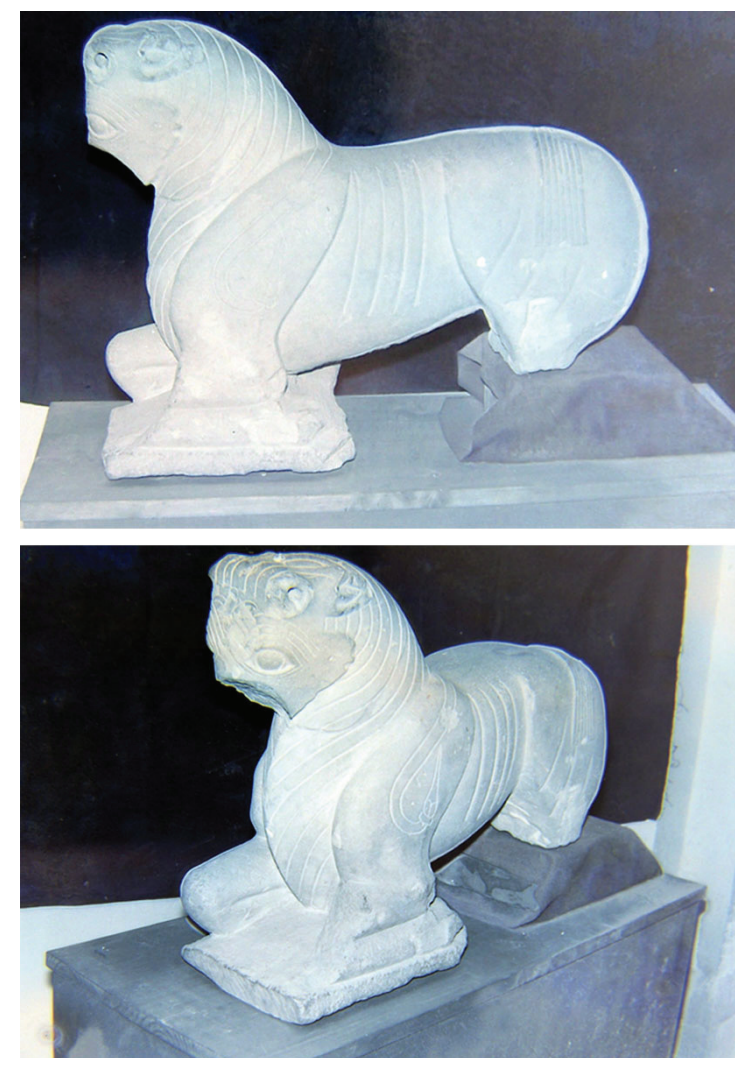

Figura 1.- Primeras fotografias del torito de Porcuna realizadas por César Cruz (Archivo: Museo de Porcuna).

"Cruz de San Pedro". Otro león echado apareció en la entrada de una casa de la Calle Sagasta en 1970. La descripción que dio su descubridor, José Santiago Torres, destacaba el volumen de la melena, por lo que parece corresponder a una figura de época romana. Actualmente no se conserva, ya que fue troceado y los fragmentos empleados en el relleno de una zona exterior del pueblo, hoy calle San José. Años antes, en la década de 1920, se encontró de forma casual una escultura representando un oso con la zarpa apoyada en una cabeza humana. Apareció en la actual Carrera de Jesús $\mathrm{n}^{\circ}$ 27, antes "Calle del Sepulcro" (Cazabán 1927). Un estudio reciente ha situado su cronología en el s. I d.C. (Beltrán y Loza 2005), revelando la continuidad de la talla en piedra en época romana. En la actualidad se conserva en el Museo Arqueológico Nacional. Esta concentración de hallazgos indica que la ciudad de Ipolca-Obulco tuvo gran importancia en la Antigüedad, y que los talleres de escultura sirvieron para mostrar y realzar la ideología de las élites dominantes (Fig. 2).

El estudio histórico y social de este centro, enfocado desde una perspectiva territorial, ha sido el objetivo del "Proyecto Porcuna", dirigido por el Dr. O. Arteaga, junto con A.M. Roos, F. Nocete y J. 


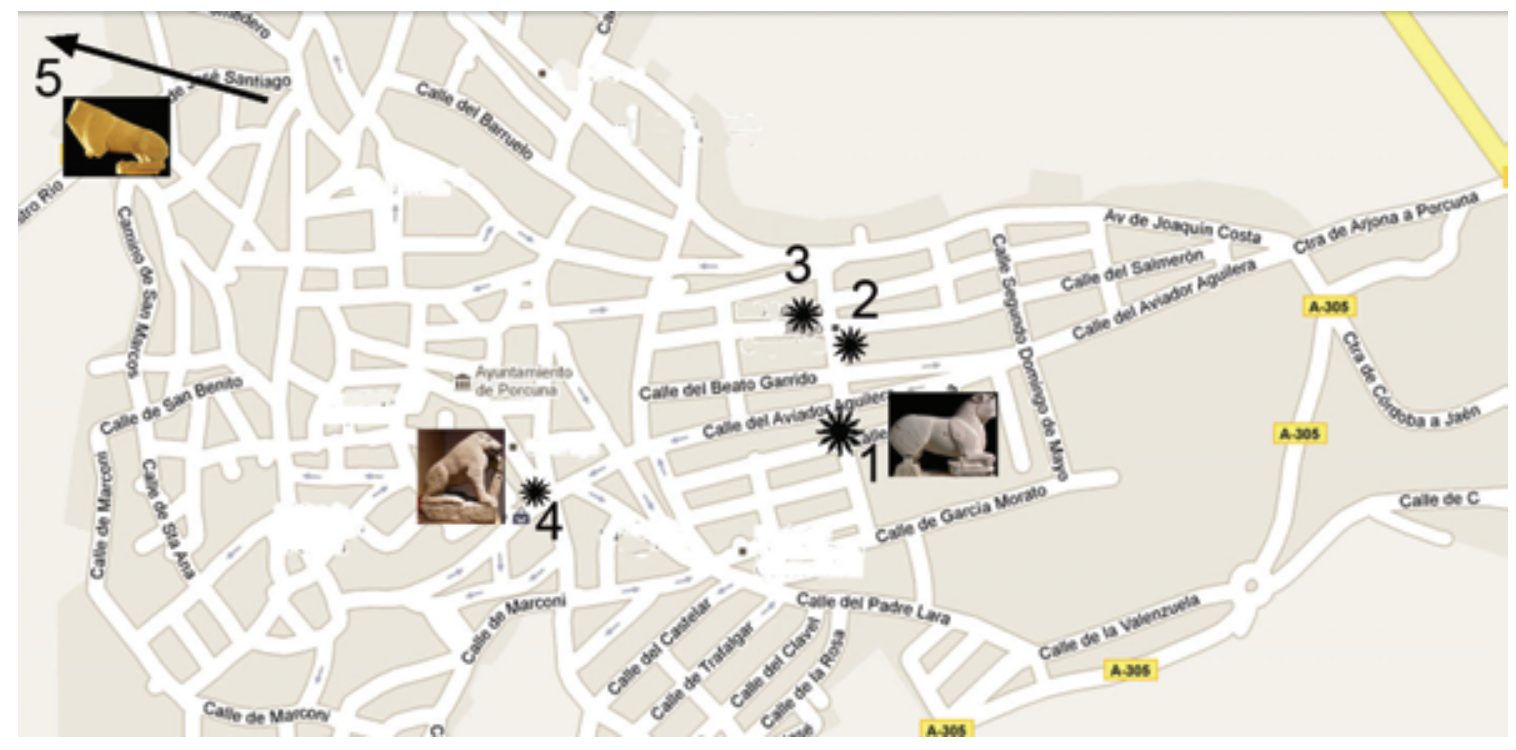

Figura 2.- Localización de los hallazgos escultóricos en el casco urbano de Porcuna. 1. "Torito"; 2. León ibero-romano; 3. Capiteles ibéricos; 4. Oso con herma; 5. Leona. Mapa base: revista Trabajos de Prehistoria (CSIC).

Ramos (Arteaga et al. 1993). En él han participado igualmente diversos arqueólogos de Porcuna y otras procedencias. Su orientación, desarrollo y resultados preliminares han sido expuestos por Arteaga (1999), y aunque buena parte de los resultados permanecen inéditos, suponen la necesaria contextualización arqueológica de obras singulares como son las escultóricas.

A pesar de haber sido muy citada en la bibliografía, la escultura del "torito" carece de un estudio específico, destacando las primeras valoraciones realizadas por Blanco (1960: 37-40), quien además proporciona fotografías de la pieza desde diversos ángulos (Blanco 1961-2, figs. 6-10) y posteriormente por Chapa (1980: 480-483), Negueruela (1992: III), León (1998: 80) y Olmos (1999: ficha 50.2). Como luego veremos, su inicial atribución a un contexto plenamente ibérico ha sido revisada por Almagro-Gorbea y Torres (2010), situándola en un momento anterior, de pleno s. VII a.C.

En este trabajo pretendemos profundizar no sólo en los aspectos formales e iconográficos, buscando sus paralelos y su contexto cultural local (Fig. 3), sino entender la concepción, planificación y realización de la pieza desde el punto de vista del escultor. Este enfoque apenas ha sido desarrollado hasta el momento en los estudios sobre estatuaria ibérica, a pesar de que permite una comprensión mucho más completa y profunda de las obras, al aflorar las ideas y la intencionalidad que subyacen a la percepción visual, así como el nivel y las limitaciones técnicas y artísticas que afectaron al producto escultórico final.

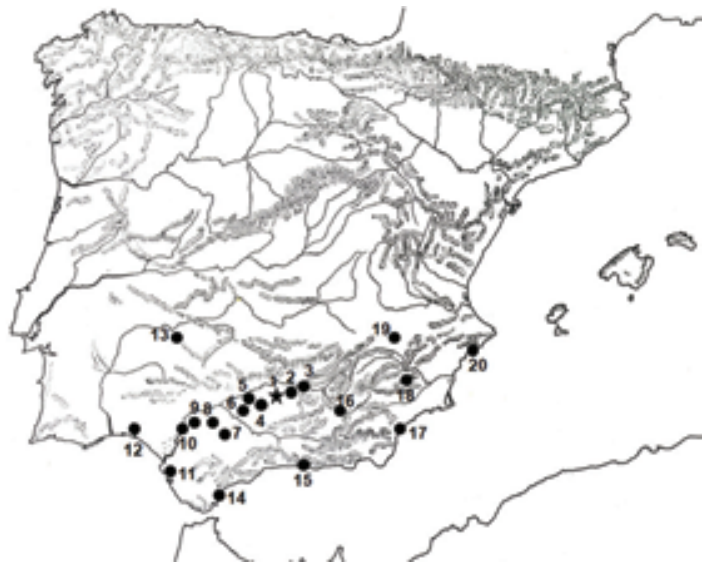

Figura 3.- Yacimientos citados en el texto: 1. Porcuna; 2. Arjona; 3. Los Villares de Andújar; 4. Santa Sofía; 5. La Victoria; 6. Santaella; 7. Osuna; 8. Montemolín; 9. Carmona; 10. Carambolo; 11. Cádiz; 12. La Joya; 13. Medellín; 14 Cerro del Prado; 15. Puente de Noy; 16. Baza; 17. Villaricos; 18. Cigarralejo; 19. Pozo Moro; 20. Villajoyosa.

\section{Descripción de la pieza}

El toro se encuentra en posición echada, con las patas dobladas sobre un plinto fino labrado en el mismo bloque. Sus dimensiones son $55,5 \mathrm{~cm}$ de alto, $70,5 \mathrm{~cm}$ de longitud y $20,5 \mathrm{~cm}$ de grosor. El peso actual de la pieza es de $83,7 \mathrm{~kg}$. Dos rasgos estructurales definen la innegable originalidad de su 
diseño: la curva del cuello, que marca la posición rebajada de la cabeza, y la línea oblicua del vientre, elevada hacia los cuartos traseros y resaltada sobre el vaciado interior de la piedra. La figura en su conjunto se aleja deliberadamente de los modelos reales para convertirse en un dibujo conceptual en el que se resalta su carácter de bóvido joven y ligero, cargado de simbolismo sagrado (Fig. 4).

El perfil correspondiente al tabique nasal marca una línea vertical que indica la posición algo rebajada de la cabeza. Dominan en ésta los ojos, grandes y con la pupila redondeada, bien diferenciada del globo ocular. Los párpados superior e inferior crean un marco bien resaltado que se refuerza con incisiones paralelas, tres por encima del primero y una bajo el segundo. Todas ellas confluían en el centro de la frente como si fueran los tallos desde los que surge la flor abierta que ocupa toda la frente, en cuyo cen- tro se sitúa un orificio circular. Seis incisiones verticales y paralelas ocupan la superficie entre cuernos, siendo la central algo más ancha, y no coincidiendo exactamente su centro con el pétalo central de la flor. Falta completamente el hocico a causa de una fractura, probablemente intencionada, pero se conservan las carrilleras, de silueta subcircular, cuya superficie ha sido especialmente alisada. En ambas, izquierda y derecha, se ha practicado un orificio con el fin de insertar un elemento accesorio.

Las orejas quedan pegadas al cuello y su forma es acorazonada, con bordes bien definidos y una espiga central que dibuja una división interior. $\mathrm{Su}$ presencia se superpone a las líneas curvas alusivas a las arrugas del cuello. Estas surgen de una línea, también incisa, que recorre longitudinalmente el cuello dorsal, y confluyen en la papada y la badana. Tras la última arruga, y con su misma morfología,
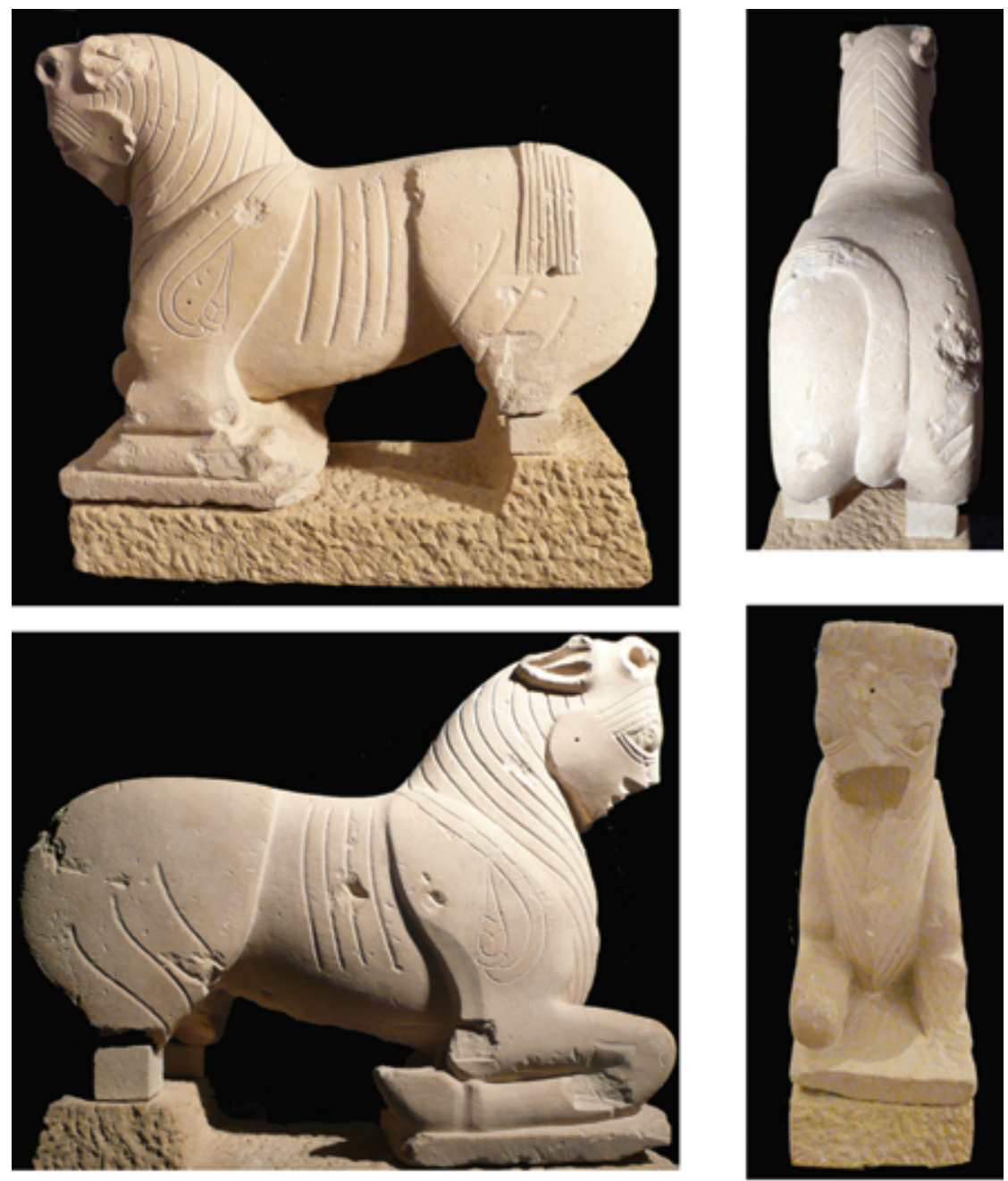

Figura 4.- El toro de Porcuna en perspectiva lateral, trasera y frontal (Foto: T. Chapa). 
se define una cinta que discurre sobre la cruz del toro y que termina en dos capullos verticales grabados en los hombros, cuyos laterales internos quedan en un plano ligeramente biselado respecto al resto.

En cada lado del tórax se trazan cuatro profundas incisiones verticales y paralelas para indicar las costillas, mientras que la línea inferior del vientre asciende de forma marcada hacia las ingles, en cuya zona se ha aludido a los órganos sexuales mediante un resalte. Nuevas incisiones, esta vez curvas y en número de tres, se localizan sobre ambos muslos. La cola, gruesa y de sección rectangular, surge entre los cuartos traseros para apoyar su extremo, en forma de mechones planos y paralelos, sobre el muslo izquierdo.

Además del orificio ya citado correspondiente a la flor frontal y a los carrillos, existen dos más, siempre en el lado izquierdo. El primero corresponde a la zona del capullo que decora el brazo, y su diámetro es similar a los anteriores. El segundo corresponde al extremo de la cola en su parte central y es algo más amplio.

Además del hocico, a la pieza le falta el tabique nasal, la rodilla delantera izquierda y el extremo de ambas patas traseras, así como su base, un delgado plinto tallado en el mismo bloque, a partir de las pezuñas que rematan las patas dobladas bajo el vientre. Algunos impactos violentos han dejado su huella, sobre todo en el lado derecho, mientras que en diversas partes de la figura, como luego veremos, se aprecia el trabajo de cinceles y otros utensilios que han intentado arañar la superficie, pero cuya intención primordial no era romper la escultura.

\section{Diseño y proceso de talla}

La modulación de esta pieza llama poderosamente la atención. Su estudio nos permite reconocer a un especialista que no practicaba la talla directa, sino que dedicaba al diseño previo un intenso trabajo de geometría plana, estableciendo una relación de medidas que resultó crucial para obtener el producto final que hoy observamos. Asimismo puede detectarse una singular capacidad para ajustar la pieza a las pequeñas desviaciones respecto al programa original que debió presentar el bloque extraído de la cantera.

Gracias a que contamos con las dimensiones casi exactas de altura y longitud de la escultura, podemos apreciar que se inserta en un rectángulo cuyo lado viene marcado por la altura (Fig.5). Situando un compás en el vértice inferior y superior, y transportando esta medida, definimos un cuadrado. Dividiendo éste en segmentos iguales, y añadiendo uno más en sentido de la longitud, formamos un rec-

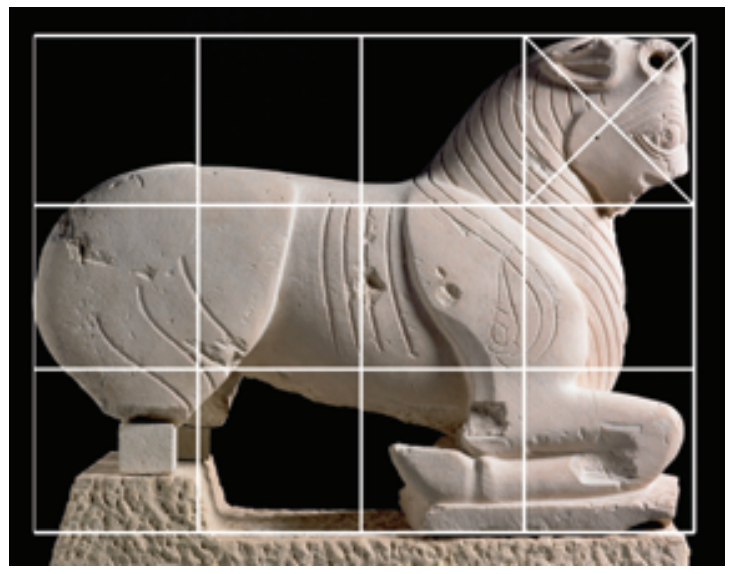

Figura 5.- Módulos empleados para "encajar" la escultura.

tángulo modulado. El toro de Porcuna encaja casi exactamente en esta modulación, lo que no puede considerarse casual. Con este cálculo se consigue por tanto una retícula de doce cuadrados que sería la que los canteros utilizaron para trasvasar las medidas del prototipo al original del bloque. Las líneas fundamentales de composición de la figura sobre el fondo servirían para indicar las áreas que debían ser vaciadas en primer lugar. Por su parte, cada cuadrado, que podría dibujarse igualmente sobre el bloque de talla, serviría como marco para distribuir los elementos interiores, tanto físicos como decorativos.

La existencia de patrones de medidas, y sobre todo de proporciones, fue algo especialmente respetado en el mundo antiguo. La idea egipcia de que las divinidades se materializaban en las esculturas implicaba que éstas debían tener unas proporciones adecuadas al mundo ideal de los dioses, y por tanto surgieron patrones normativos al respecto. Para ello se desarrollaron la geometría y los recursos auxiliares (retículas, módulos, etc.) al servicio de la representación del orden divino (Kielland 1987: 7). Más tarde, este mismo deseo aplicado a fines muy diversos, llevará al desarrollo de la proporción áurea (Gómez Rendón 1998).

Una vez estipulado el diseño, es preciso iniciar el proceso de talla, momento en el que se hace necesaria la selección de una cantera que cumpla varios requisitos: la idoneidad de la piedra, la disponibilidad de bloques del tamaño adecuado y la accesibilidad para el desarrollo del trabajo. El escultor, sin duda, transmitiría sus criterios a los canteros y probablemente participaría directamente en este trabajo, puesto que debería asegurarse de que la piedra cumplía los requisitos de tamaño y calidad que requería la talla.

Por el momento no contamos con análisis que hayan podido determinar ni los componentes prin- 


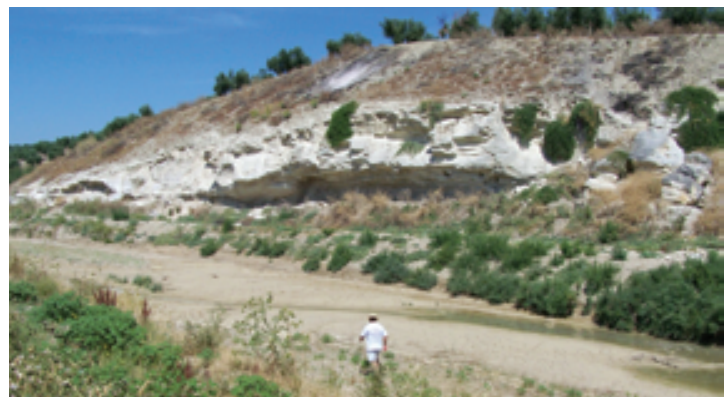

Figura 6.- Cantera de Las Albarizas en Porcuna (Foto: L. E. Vallejo).

cipales ni los elementos traza de la piedra en la que se ha labrado el "torito", dado que la obtención de datos a partir de muestreos superficiales no destructivos no resultan demasiado diagnósticos. Sin embargo, aparentemente sus características coinciden con la de las canteras de la propia población de Porcuna (Fig. 6), cuyos planos sedimentarios uniformes no exceden los $30 \mathrm{~cm}$ de grosor, aunque pueden ser de largo y alto variables, lo que resulta compatible con esta pieza. Una vez retiradas las partes deposicionales blandas, de color más amarillento, que caracterizan los planos intermedios de los niveles calizos, se obtiene una piedra blanca, de grano muy fino. En la actualidad los canteros de Porcuna la denominan "piedra blanca del campo", por localizarse a veces a cielo abierto como producto de antiguas canteras, algunos de cuyos bloques han quedado en superficie. Al aflorar y ser lavadas por la lluvia, y luego retiradas por los agricultores, forman conjuntos ordenados que utilizan a veces los canteros para trabajos especiales.

Para la realización del toro echado, teniendo en cuenta la figura completa, se precisaría un bloque de unos $175 \mathrm{~kg}$, teniendo en cuenta la densidad de la piedra y el tamaño mínimo necesario para su labra. Una vez terminado, el toro pesaría en total unos 100 $\mathrm{kg}$, descontando las zonas extraídas. Las características del bloque inicial condicionaron sin duda la labra del toro, y el adelgazamiento apreciable en su perfil frontal cabe adjudicarlo a esta causa. A su vez, el estrato al que pertenece este bloque tiene un grosor muy limitado, lo que provoca que los flancos laterales del toro correspondan prácticamente con los planos laterales de aquel, que podría conceptualizarse como un paralelepípedo de perfil troncocónico, de base mayor y altura progresivamente en disminución (Fig. 7).

Las observaciones sobre la talla de esta pieza se apoyan en los datos obtenidos desde 2004 en el "Taller Experimental de Escultura" del Museo de Porcuna, en donde se trabaja investigando y reproduciendo

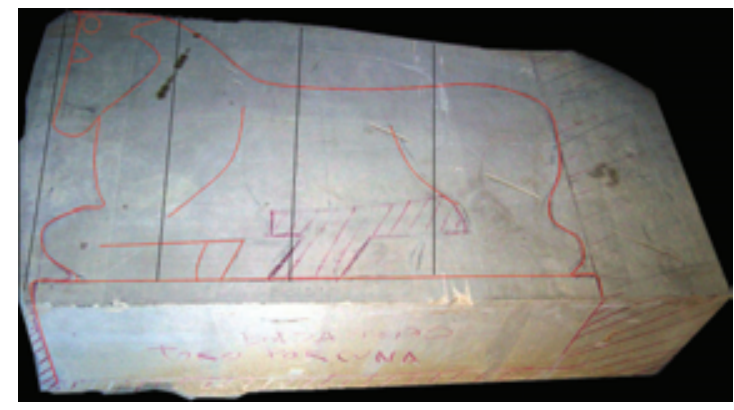

Figura 7.- Bloque de piedra con dibujo inicial del toro. Taller experimental del Museo de Porcuna (Foto: L.E. Vallejo).

tanto la talla y las huellas de las herramientas como la decoración, los tratamientos superficiales y los procesos de destrucción de las esculturas. Para ello se ha contado con una reproducción en piedra del "torito" a escala natural, realizada por la empresa CRUMAR a partir de un escaneo 3D de la pieza original realizado por el Centro Tecnológico Andaluz de la Piedra (Macael) en el Museo de Jaén.

Esto nos permite confirmar que, una vez extraído con éxito el bloque, se procedió a tallar la escultura trasvasando las medidas de un modelo previo. Para ello se utiliza el puntero grande y cinceles anchos de cantero, con los que se regulariza la piedra al máximo. Ya se ha señalado que esta figura no pudo ser producto de una talla directa, donde el escultor trabajaba sin modelos. Todos los detalles estructurales de anatomía, huecos y diseño de elementos secundarios consiguen un acierto tan alto debido a la seguridad que muestran los artesanos sobre el lugar que va a ocupar cada elemento, y esto es posible gracias a que disponen de modelos a escala en barro o yeso, o incluso en madera, lo que permite a su vez afianzar los módulos y submódulos en el bloque.

Sobre éste debió marcarse un eje de simetría central, origen del nacimiento de la anatomía de la pieza y punto cero del que parte hacia fuera cualquier medida o desviación de este eje, como veremos más adelante. La siguiente fase es el recorte con conceptos de relieve desde uno de los lados del perfil de la figura exterior. En esta fase se utilizarían cinceles planos y curvos de media caña de unos $3 \mathrm{~cm}$ de anchura. Se elimina el fondo sobrante progresivamente, pasando del bajorrelieve, al medio y alto relieve, momento en el que se aprovecha para vaciar también los huecos de la figura. En este caso observamos cómo el aire entre la línea del vientre y el podio, en su relación con las patas traseras y delanteras, se realiza con sumo cuidado, convirtiéndose en una de las características de la escuela escultórica de Ipolca: el virtuoso uso de los huecos de animales y seres humanos con respecto a las enormes masas de piedra 
que son sostenidas, como podremos ver en las obras posteriores del novillo-toro o en el guerrero alanceando al enemigo de Cerrillo Blanco (Negueruela 1990: fig, 10). En el caso del "torito", el hueco sirve para estilizar la figura, dar movimiento y reseñar los órganos sexuales masculinos.

Definido el perfil exterior e interior, a continuación se tallan a distintos niveles las partes generales en las que se subdivide la figura. Aquí se utilizan cinceles planos más pequeños, rectos y curvos, además de punteros medios para definir planos y aristas interiores. Los cuartos traseros y las patas de atrás se tallan como un todo, formando un primer cuerpo; un segundo plano corresponde a la línea del vientre, y el tercero o principal, engloba toda la zona de la cabeza, morro, pescuezo, aguja, falda o aleta, espaldilla y patas delanteras, siguiendo la nomenclatura anatómica del animal de referencia. Una vez terminado el proceso por uno de los lados, se repetiría desde el otro perfil de la figura.

El eje central de referencia al que antes aludíamos, ocupa ahora una especial importancia, ya que la figura es sometida a la talla, desde el frente, de la cabeza, línea de falda y badana, y posición de las patas delanteras. Aquí el escultor juega con el uso virtuoso de su oficio, desviando el eje de simetría hacia la derecha y superponiendo a éste perpendicularmente la línea horizontal de cuernos. Con esta sutileza consigue girar 5 grados la cara del animal, rompiendo su simetría-quietud e introduciendo una vida propia a la composición de la que carecería la pieza si su trazado fuera estrictamente frontal. No se trata de un fallo, sino de una huella de grandeza del artífice (Fig. 8).

La figura ahora es tratada en todos sus flancos con técnicas de rebaje consecutivo, de manera que se atacan los planos geométricos producto de la subdivisión de las tres partes anatómicas principales hasta hacerlos desaparecer. Las suaves transiciones de los planos laterales de las partes traseras, vientre y partes delanteras, son difuminadas con sumo cuidado. Del mismo modo, las aristas principales de la figura en torno al eje de simetría del cuello, pescuezo y falda son definidas y perfeccionadas.

Con la pieza ya modelada y revisadas sus extremidades, se establece la relación de las líneas de la frente con respecto a las de las rodillas flexionadas y punto del podio, de las líneas de la frente y laterales de la cabeza con respecto al mismo podio, así como la posición de la cadera y partes traseras, reservas para el volumen del rabo, pezuñas, orejas, ojos, y boca, etc. Todo esto se talla con pequeños cinceles engastados en mangos de madera con técnicas de ebanista, que son lijados a continuación. Los pocos estudios que hasta el momento se han centrado en el reconocimiento del utillaje empleado en el proceso escultórico reconocen que el cincel recto fue un

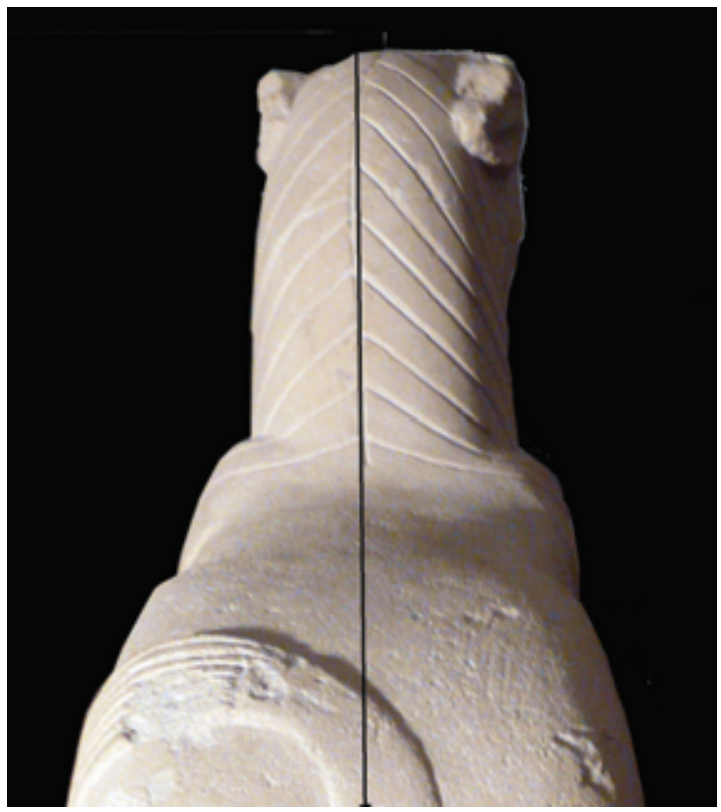

Figura 8.- Ligera desviación hacia la derecha del final del cuello respecto al eje central de la pieza (Foto: $\mathrm{T}$. Chapa).

instrumento fundamental en los talleres ibéricos (Izquierdo 2000: 391).

La pieza, así, está dispuesta para la siguiente fase, en la cual se emplean estiletes finos con distintas secciones. Punteros muy afilados y punteros con sección de pico de gorrión en "V", se combinan con otros biselados, fabricados para la pieza. Una vez dibujados, los elementos se tallan de menos a más, hasta conseguir la profundidad adecuada, siendo repasadas y perfeccionadas las líneas. Pequeños orificios circulares horadan la superficie para los engastes metálicos. Para su realización no hubo necesidad de emplear un trépano complejo, sino una acción por frotación rápida con las dos manos haciendo girar un pequeño cincel ligeramente apuntado. Este tipo de trabajo se atestigua desde el s. VII a. C. en Grecia, aunque al tratarse de esculturas en mármol más duro, se realizó con un taladro unido a un arco (Palagia 2006: 253; con bibliografía anterior).

Si bien en algunos pasos del proceso de labra pudieron emplearse utensilios de madera, los principales instrumentos serían básicamente de hierro. La expansión de este tipo de metalurgia es una de las características apreciables desde el s. VII en esta zona, y muestras de ello son los hornos y toberas de esta fecha localizados en Los Villares de Andújar (Arboledas 2010: 126). Sin embargo, conseguir un instrumental completo y variado en este material fue uno de los elementos suntuarios asociados a los talleres de escultores, en donde debieron existir forjas para la creación y ajuste de las herramientas (Fig. 9). 


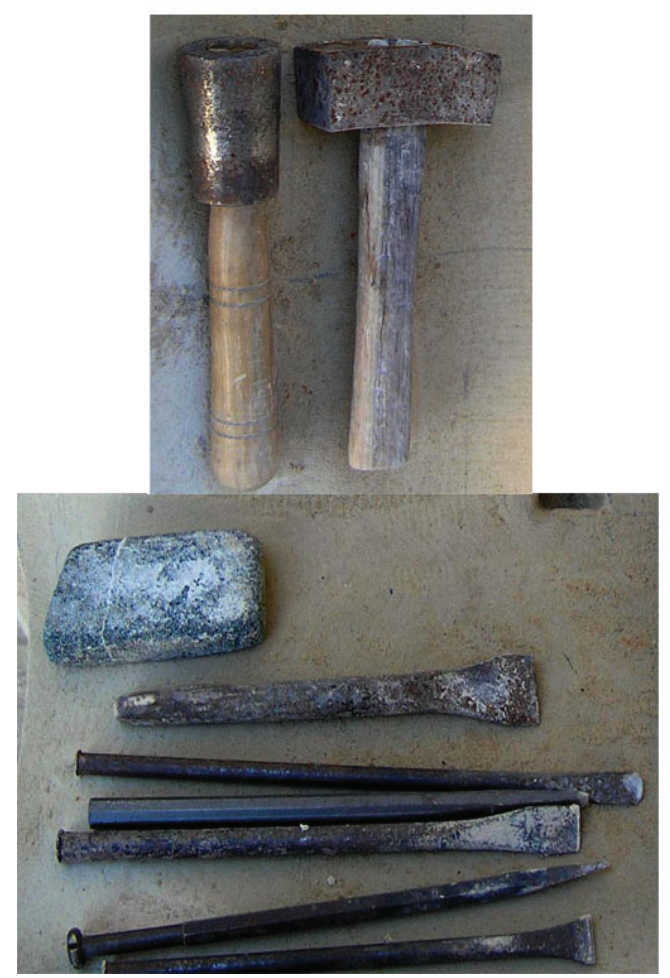

Figura 9.- Herramientas de escultor tradicional y piedra para "apomazar" o pulir superficies. Taller de Francisco Aguilera de Dios, Porcuna (Foto: T. Chapa).

\section{Adornos florales y elementos accesorios}

Uno de los aspectos que más llama la atención en esta figura es la presencia de motivos florales incisos, tanto sobre la frente como en la superficie de las paletas (Fig. 10). Indudablemente, los tres corresponden a la misma planta, con el capullo cerrado en los laterales y abierto en la zona frontal. Blanco (1961-1962: 186) y García Bellido (1980: 69) la identificaron con un lirio, opinión compartida por Alberto Herrero, investigador científico del Real Jardín Botánico, al que hemos consultado este punto. Por su parte, Negueruela (1990: 28) lo hace con la Nymphaea coerulea o "loto azul".

El diseño de estos motivos sigue una secuencia en la que la flor abierta tiene una posición central respecto a los capullos. Se emplea aquí libremente una alternancia flor/capullo que resulta habitual en los motivos decorativos que incluyen cadenas de lotos. Es el caso de los ejemplos de ambiente fenicio y tartesio que, sobre distintos soportes, se han recogido en el estudio de la decoración vegetal de los pithoi de Carmona (Belén et al. 1997: 160-163, fig. 37). El sentido de esta secuencia, como indica Olmos (2003: 40), es simbolizar el jardín mágico que forma parte del paisaje divino, y al que solo los más poderosos entre los humanos pueden acceder. Blanco (1961-1962: 186-187), observando la cabeza y el cuello del toro desde una posición elevada, llegó a proponer la lectura de las líneas del cuello "como una palmeta... [a la que] se le añadieron al pie los mismos apéndices que decoran las palmetas terminales de los jarros de bronce orientalizantes" (Fig. 11). El sentido de las flores de loto ha sido analizado con detalle en el proyecto "Flora Ibérica", al que remitimos para su inventario y revisión de significados (Mata et al. 2010: 117-127).

Estas incisiones florales no pueden desvincularse de los orificios situados en la cabeza, paleta izquierda y extremo de la cola del toro, destinados seguramente a embutir otras piezas complementarias. A ellos hay que añadir los cuernos, también postizos, que terminarían de delinear la silueta del bóvido.
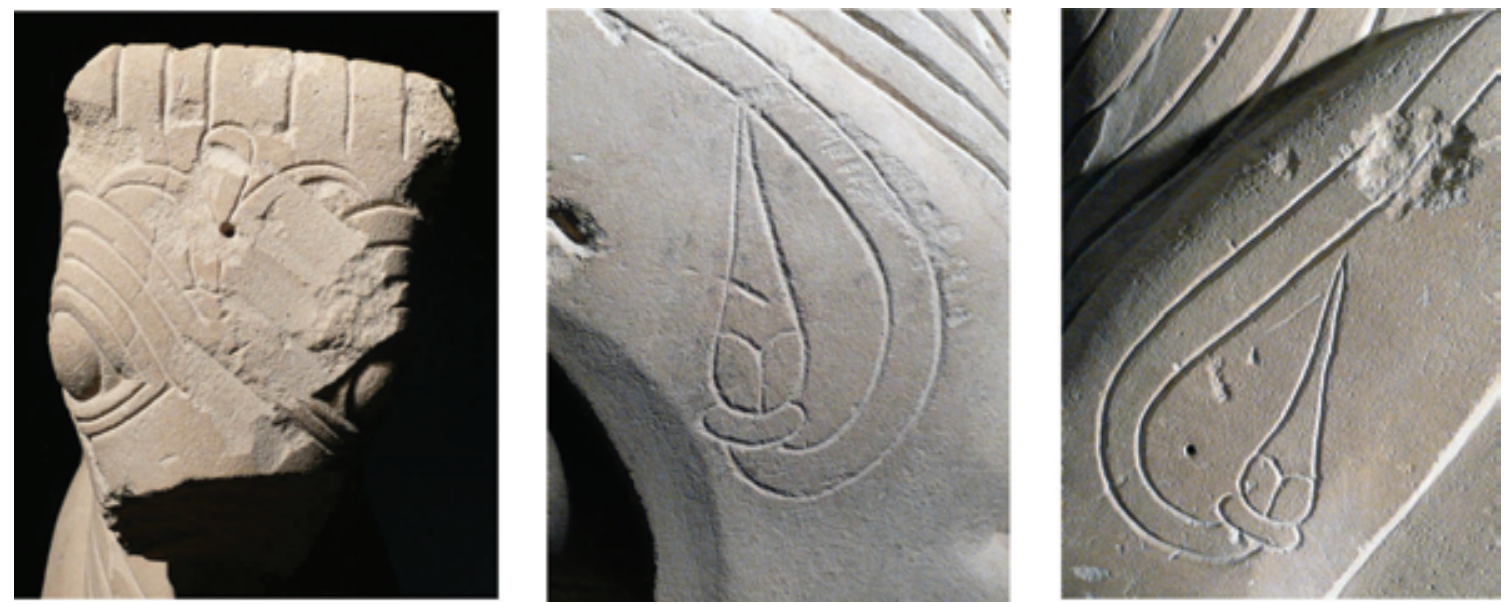

Figura 10.- Detalle de la flor frontal y los capullos laterales (Foto: T. Chapa). 

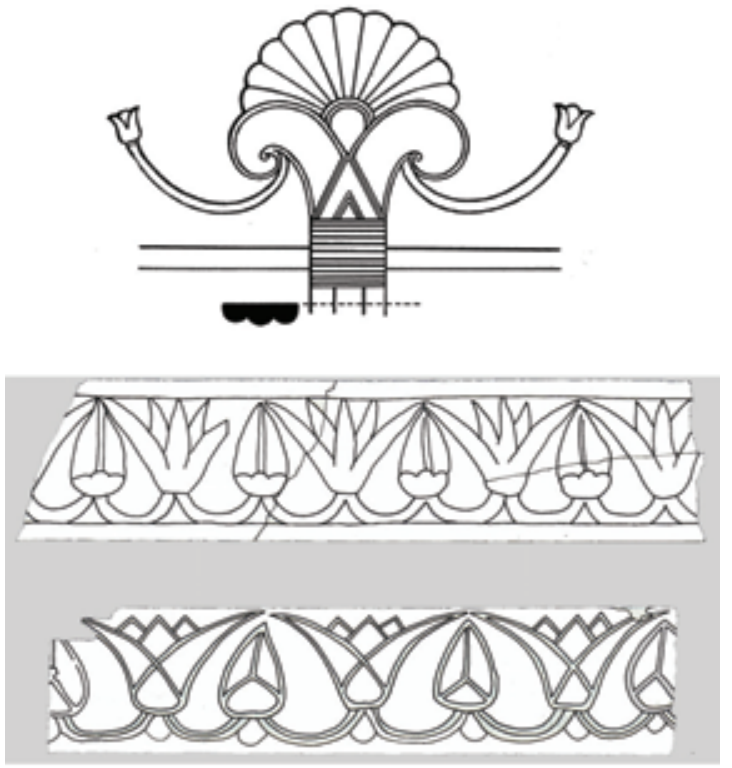

Figura 11.- Arriba: composición de palmeta y flores en el jarro de Niebla (a partir de García Bellido 1960, fig. 17); Abajo: Decoración de flores abiertas y capullos en los pithoi de Carmona (a partir de Belén et al. 1997, fig. 37).

Las alusiones a estos elementos accesorios han sido muy escuetas. Únicamente Negueruela (1990: 27-28) ha valorado algo más este aspecto, proponiendo que el aplique frontal reproduciría la forma de la flor incisa, mientras que en las carrilleras y la paleta izquierda se adosarían rosetas circulares. Como materia de los cuernos propone el asta natural o el bronce. (Fig. 12)

Las piezas aplicadas no son un recurso habitual de los escultores ibéricos, aunque los talleres de Porcuna son sin duda una excepción, puesto que en las figuras de Cerrillo Blanco se aprecian orificios con el fin de completar la decoración de los cascos de los guerreros, introducir la madera para las astas de las lanzas o añadir posibles objetos como

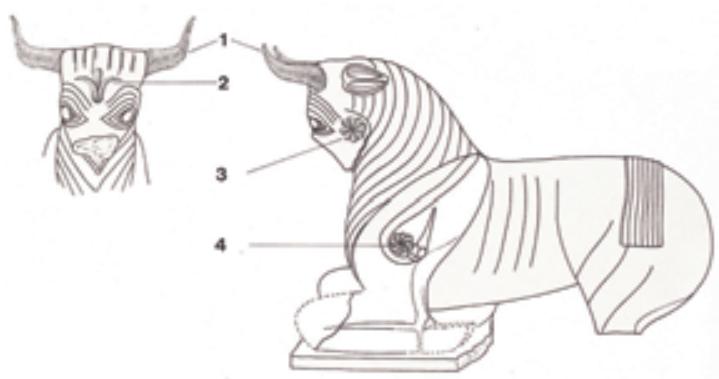

Figura 12.- Propuesta de apliques según Negueruela (1992, p. 11). el que llevaría el personaje portador de perdices (González Navarrete 1987, n 23). Asimismo, en el monumento de Pozo Moro, dos de las figuras de león y el jabalí bifronte presentan orificios, seguramente con la misma finalidad (Almagro-Gorbea 1983: 194)

De todos los elementos postizos, los más frecuentes son los cuernos y, eventualmente, las orejas. Sin duda esto tiene que ver con la dificultad que representa la talla de estos apéndices, que quedan exentos y por tanto muy amenazados de fractura. Por esta causa, y por el efectismo que sin duda tendría la cornamenta postiza, especialmente si fuera metálica, se recurrió a esta técnica en los momentos iniciales de la escultura ibérica y ocasionalmente se volvió a emplear a lo largo del tiempo en otras ocasiones. Este es uno de los rasgos esenciales de un grupo específico de bóvidos distribuidos por la zona mediterránea, desde Valencia a Murcia (Chapa 2005 y 2005-2006), aunque los paralelos más próximos del toro de Porcuna, como luego veremos, se encuentran en la vecina población de Arjona (García Bellido 1980: 70) o en territorio cordobés, donde contamos con ejemplares como los de La Victoria (Vaquerizo 1999, lam. 95) o Santa Sofía-El Polvillo (Morena 2004) (Fig. 13).

En cuanto a los apliques situados sobre la testuz, las carrilleras y el lateral izquierdo del toro de Porcuna, algunos detalles de la propia estatua nos ayudan a rastrear estos elementos accesorios. Una revisión cuidadosa de la superficie pétrea permite apreciar huellas diagonales de cincel en la zona de la frente, mientras que sobre los bordes de la cinta que termina en el capullo derecho se observan marcas de raspado, más suaves y cortas. Un golpe más fuerte y de bordes subcirculares se observa sobre la cinta del lado derecho. La zona de las carrilleras ha quedado indemne, pero su decoración pudo ir unida a la del hocico en forma de un posible atalaje, de manera que al romper esta parte de la boca los elementos decorativos podrían haberse arrancado con más facilidad. También hay golpes horizontales en el inicio del remate de la cola, donde los mechones en resalte se separan mediante profundos surcos, terminando en un nuevo orificio. En el cuarto trasero izquierdo se aprecian marcas de cincel en sentido horizontal y de carácter superficial sobre las marcas oblicuas incisas, así como en el entorno de las dos pezuñas delanteras, lo que podría indicar nuevos elementos adheridos que aparentemente no fueron sujetos con remaches. Todas estas huellas parecen ir destinadas a arrancar los apliques que decorarían la superficie del animal y sus posibles elementos asociados, por lo que parece lógico pensar que se trataría de obje- 

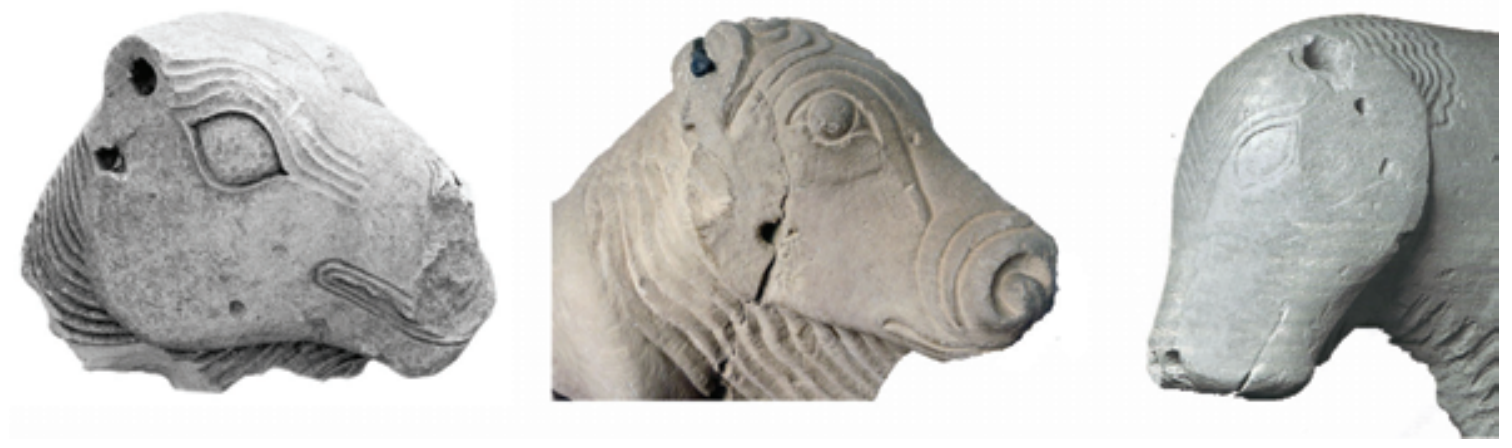

Figura 13.- Cabezas de toros de Santa Sofía (según Morena 2004), Arjona (Foto: T. Chapa) y La Victoria (a partir de Vaquerizo 1999: Lam. 95).

tos elaborados en una materia prima valiosa, como oro, plata, bronce y, quizá, ricas telas.

La aplicación directa de láminas de oro, delgadas y flexibles, no es compatible con la presencia de remaches, que sólo son adecuados cuando el elemento que sujetan es rígido y de cierto grosor. Por tanto, en el caso de emplearse únicamente el oro, éste debería ir adherido a un soporte, ya fuera madera o una tela gruesa. En cambio, tanto la plata como el bronce admitirían adherirse a la piedra mediante un clavo. Ambas materias primas eran empleadas con frecuencia en estos momentos para la fabricación de objetos suntuarios, que conocemos a través de los ajuares funerarios y otros contextos (Rovira 1995: 485). La palmeta de "tipo rodio" conservada en la boca de un jarro orientalizante procedente de Granada, fue repujada sobre lámina de plata y adherida a su soporte mediante un remache (Jiménez Ávila 2002, figs. 63 y 64).

En el caso del bronce, su tonalidad exterior podría haber imitado el aspecto del oro o de la plata si en la aleación se empleara un porcentaje inusualmente alto de estaño. Los análisis de las piezas de bronce de la necrópolis de Medellín muestran un empleo muy desigual de este mineral, que en algunos casos roza hasta el $20 \%$, aunque no se aprecia un patrón significativamente orientado (Rovira 2008: 848$850)$. En cualquier caso, a partir de un $11 \%$ el color del bronce se acercaría al de los metales nobles. Es de suponer que este efecto era conocido en la Península Ibérica, como lo prueba la presencia en la tumba 17 de la necrópolis de La Joya de un espejo con mango de marfil, atribuyéndose su contenido relativamente bajo en estaño a la pérdida de la lámina superficial (Escalera Ureña 1978: 217). En la misma necrópolis se han recuperado palmetas y adornos de pequeño tamaño que ajustaban en otros elementos metálicos mediante remaches (Garrido y Orta 1978: figs. 48g y 78, 1).

Desde luego, no debe olvidarse la posibilidad de que sobre una base de bronce se aplicara una lá- mina de oro o de plata que enriqueciera la pieza y aportara un hipotético contraste de color. En el entorno peninsular, el empleo de placas doradas sobre figuras de bronce se atestigua en la conocida figura del "sacerdote" o dios "Ptah" de Cádiz, que a pesar de su probable carácter importado (Jiménez Ávila 2002: 289) acabó insertándose en el mundo fenicio occidental. En cuanto al empleo de láminas de plata, puede citarse como ejemplo bien documentado la pieza de cinturón encontrada en la tumba 20 de la necrópolis de Les Casetes de Villajoyosa (García Gandía, 2009, fig. 135). Seguramente esta práctica fue frecuente en las piezas de lujo, aunque su conservación resulta muy difícil y en general se ha perdido la lámina superficial más vistosa, al menos a simple vista. Es lo que sucede en la placa de cinturón de la tumba 12 de La Joya (Garrido y Orta, 1978, fig. 9), en donde la presencia de plata sólo pudo ser documentada mediante analítica. ). En épocas más tardías se ha documentado la utilización de finas láminas de plata para recubrir las joyas representadas en algunas esculturas ibéricas, como la Dama de Baza (Gómez et al. 2010; 2011).

Aunque en otras áreas mediterráneas los elementos accesorios se hayan empleado con frecuencia, en general su estudio, como señala Patay-Horváth (2009: 92), no ha sido bien sistematizado. Como es habitual, es en el arte griego donde ha recibido más atención, correspondiendo a Ridgway (1990) unas interesantes reflexiones de carácter general. Los apliques del toro de Porcuna entrarían en un grupo que denomina como "realista", que correspondería a elementos existentes en el registro material de la época, como joyas, adornos, atalajes, armamento, instrumental, etc. Autores como Schäfer (1996: 72) consideran que el inicio de los apliques metálicos sobre la escultura en piedra tiene sus precedentes en la técnica del sphyrelaton, consistente en la aplicación de hojas metálicas martilladas sobre un núcleo de madera o de otro material. A pesar de las dificultades de conservación de este tipo de piezas, se 


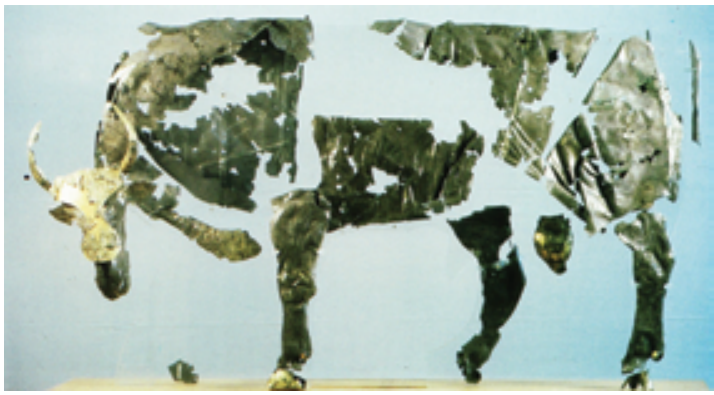

Figura 14.- Láminas de bronce y oro recubriendo una escultura de toro originalmente de madera. Delfos, s. VI a.C. (Rolley, 1994, fig. 3).

conocen algunas muy llamativas, como la cabeza de marfil con cabellera de plata dorada y oro procedente de la favissa o depósito votivo de Delfos, así como la placa ornamental representando un toro del mismo yacimiento, realizada en plata recubierta de lámina de oro, sobre cuya frente y tabique nasal todavía se aprecia una cinta o placa ornamental con un disco. Ambas piezas han sido fechadas a mediados del s. VI a.C. (Rolley 1994, figs. 3 y 5) (Fig. 14).

Ciertamente, el contraste que se consigue empleando metales brillantes, como el oro y la plata, sobre superficies de color oscuro, de tipo madera o bronce, no solo convierte a las piezas en más valiosas, sino que añade un efectismo cromático notable a esta combinación. El conocido rhyton micénico en forma de cabeza de toro, adornado con una roseta de oro en la frente, cuernos y hocico dorados, es un caso significativo (Matz 1960: 162) (Fig. 15). Sin embargo, el color claro de la piedra, sea mármol o caliza blanca, como la empleada en el toro de Porcuna, nos mueve a plantear una pregunta que también se hizo Ridgway (1990: 199): ¿por qué añadir piezas metálicas a las esculturas cuando su presencia puede resolverse mediante motivos pintados? Esta autora se decanta por hacer descender esta costumbre de épocas anteriores, en las que las imágenes de madera iban cubiertas con joyas y ricos vestidos, mantos y paños adornados con piezas cosidas. Sin embargo, como ella misma advierte, es distinto el concepto de imagen tradicional de vestir, a la que se van añadiendo con el tiempo los elementos accesorios, que el caso de las esculturas, que planifican su uso desde el primer momento como parte del diseño y efecto visual de las piezas.

Esto nos lleva a recordar la propuesta tradicional según la cual la escultura ibérica pasó por una fase "xoánica" de talla en madera que sería anterior al desarrollo de la estatuaria en piedra. Estas reflexiones se realizaron a la luz de algunas esculturas de león del área cordobesa, para las que se propuso un modelo de trabajo más propio de la carpintería (García y Bellido 1943: 78-80). En realidad, como señala argumentadamente Donohue (1988) para el mundo griego, lo más probable es que ambas técnicas se emplearan simultáneamente, dadas las grandes diferencias tanto en la obtención de la materia prima como en la metodología de trabajo que se aplica a estos dos materiales, lo que no quiere decir que no se tomaran prestadas algunas técnicas decorativas de un tipo de talla a otro.

También se ha resaltado la posible inspiración del toro de Porcuna en los bóvidos grabados sobre piezas de marfil y encontrados en contextos fenicios y tartésicos. Además de los surcos incisos que caracterizan el cuerpo del animal, el color intensamente blanco de la piedra ha podido influir en esta apreciación. Ciertamente, la costumbre de insertar láminas y piezas accesorias de oro, plata, ámbar, vidrio y otros materiales fue una práctica común en los objetos ebúrneos de mayor calidad, y quizás deban entenderse así algunos elementos del jarro conservado en el Museo Lázaro Galdiano (Jiménez Ávila 2002: Lam. V, no 10), cuya morfología y decoración de palmetas ha llevado a Belén y Marín

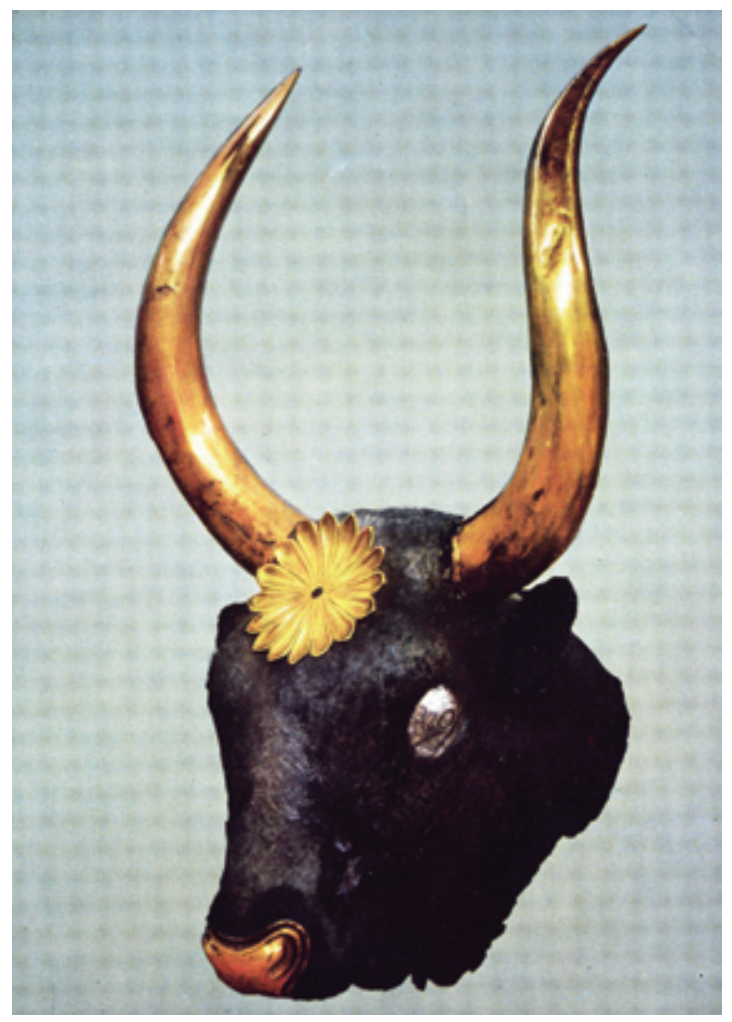

Figura 15.- Rhyton micénico en forma de cabeza de toro decorado con placas de oro y plata (Matz, 1960; 162). 


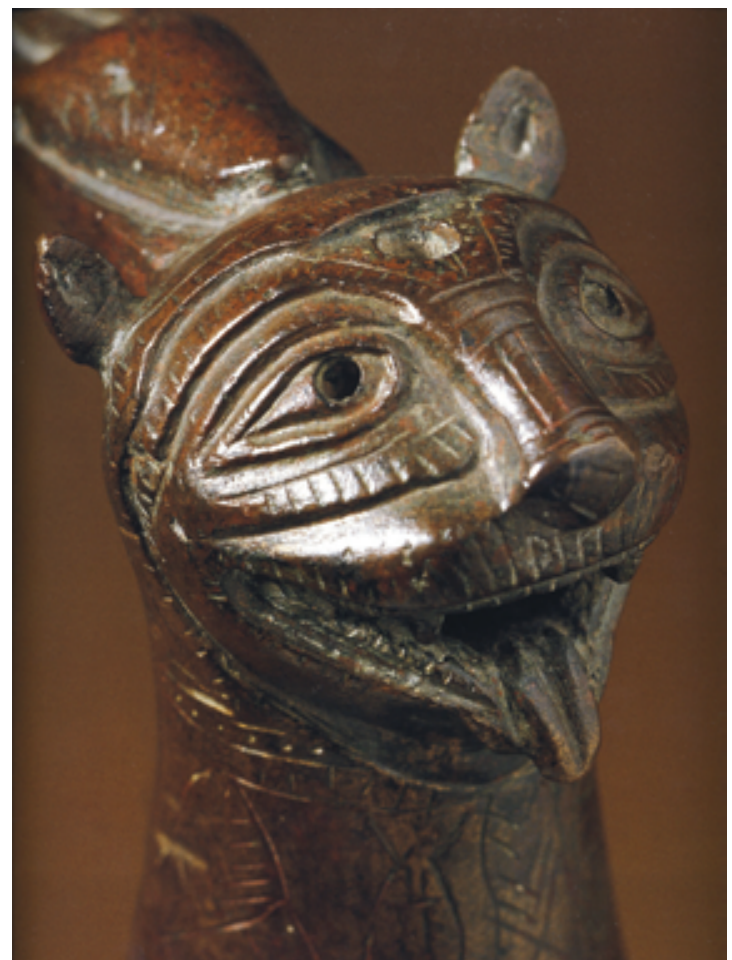

Figura 16.- Cabeza leonina del jarro del Museo Lázaro Galdiano (a partir de Blánquez 2003: 13).

Ceballos (2002) a considerar esta pieza como alusiva a la divinidad femenina (Fig. 16).

Últimamente se ha valorado el carácter sacrificial del toro como ofrenda valiosa y los restos de fauna recuperados en el santuario de Montemolín parecen confirmarlo (Chaves et al. 2000). La propuesta de Amores y Escacena (2003), basada en el estudio del depósito de piezas áureas de El Carambolo, incluye además el empleo de ciertas joyas como elementos para "vestir" al toro del sacrificio, ya sea cosiéndolas a telas que cubrirían su cuerpo al estilo de un "dorsuale" o sujetándolas a la cabeza mediante cordones, de forma que fueran visibles sobre su frente. Esta última hipótesis se relaciona con los rebajes en forma de rectángulo vertical de lados largos cóncavos que presentan algunos toros del área mediterránea, y que servirían para adherir apliques metálicos con esta forma. De esta manera se expuso en su día el toro de Villajoyosa (Llobregat 1974), al que en la actualidad se han retirado los apliques reconstructivos (Fig. 17).

En definitiva, debemos pensar que el "torito" llevaba un complejo sistema de adornos accesorios en la cabeza, consistente en dos discos metálicos situados sobre los carrillos que seguramente enlazarían con otro elemento correspondiente al morro. $\mathrm{Al}$ romper éste, esta pieza se pudo liberar y los discos
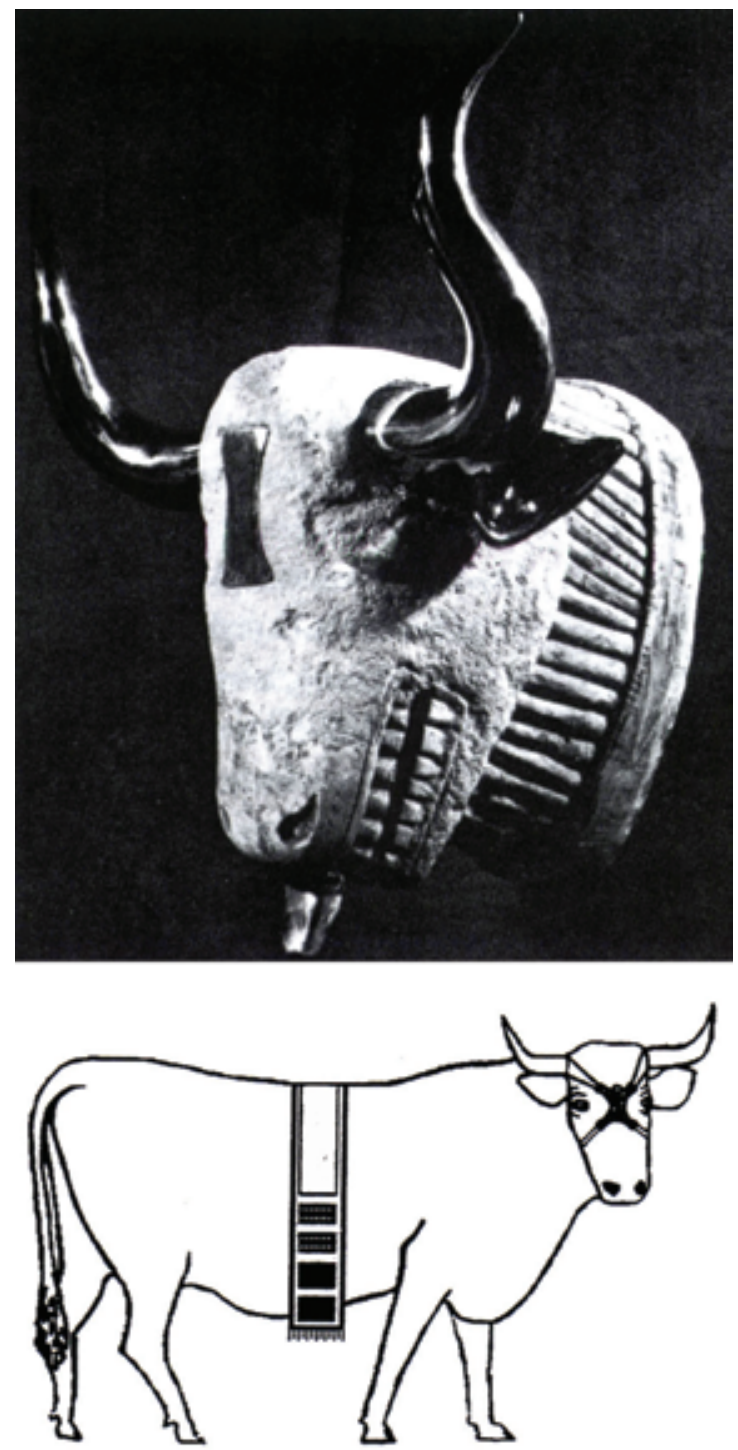

Figura 17.- Arriba: Cabeza de toro de Villajoyosa (Alicante) con apliques metálicos (según Llobregat 1974, fig. 3); Abajo: Propuesta de empleo de ciertas joyas de El Carambolo como adorno de toros sacrificiales (según Amores y Escacena 2003, fig. 4).

se extraerían fácilmente de los orificios de sujeción. Además, otro elemento -palmeta, flor, o más probablemente roseta-, ocuparía la frente, pudiendo estar unido o no al resto del cabezal. Los cuernos postizos seguramente serían también metálicos o tendrían esta apariencia, añadiendo brillo y color a toda la zona de la cabeza (Fig. 18).

Es más problemática la interpretación de los elementos que adornarían el cuerpo. Los dos orificios de sujeción restantes se encuentran en el lado 


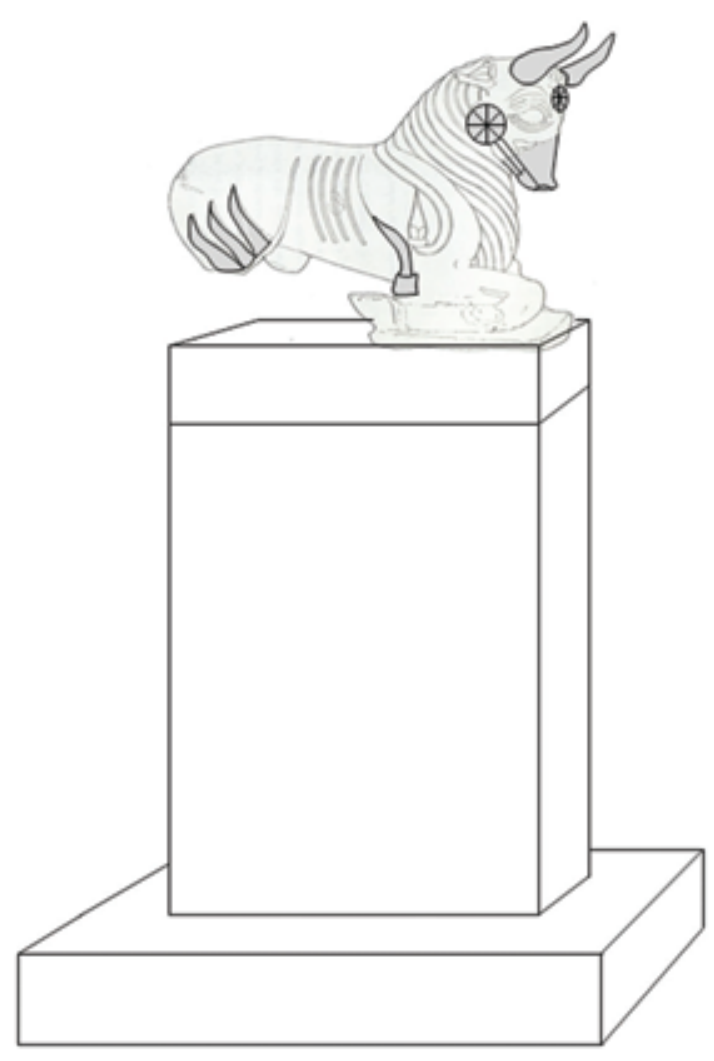

Figura 18.- Posible apariencia del toro con algunos elementos accesorios. Tanto esta propuesta como su posición sobre un pilar son meramente orientativas y no pretenden ofrecer formas o proporciones originales.

izquierdo del animal, sin que su posición apunte claramente la naturaleza de la posible estructura decorativa. Por otro lado, sobre ambos codos, pero especialmente apreciable en el derecho, hay unas "cajas" rectangulares que pudieron servir de encaje y soporte de nuevos elementos (Fig. 19). Las huellas incisas sobre el tallo de la flor derecha no son consecuencia del arranque de piezas que siguieran la forma del tallo, sino del raspado que pudo producir una placa más amplia situada sobre el brazo. La correlación de todos los elementos -hocico, carrilleras, frontal, orificios laterales- nos lleva incluso a pensar en un atalaje completo, asociado quizás a ricas telas asociadas a los accesorios metálicos. Aunque el toro está echado, la presencia de una divinidad aludida o representada sobre él parece remitirnos a una iconografía ampliamente extendida por el Próximo Oriente, donde los dioses aparecen sobre estos y otros animales, y a veces dirigiendo un carro tirado por toros (Green 2003).

El hecho de que algunas decoraciones incisas quedaran cubiertas por las piezas accesorias puede ser interpretado como fruto de ceremoniales con-
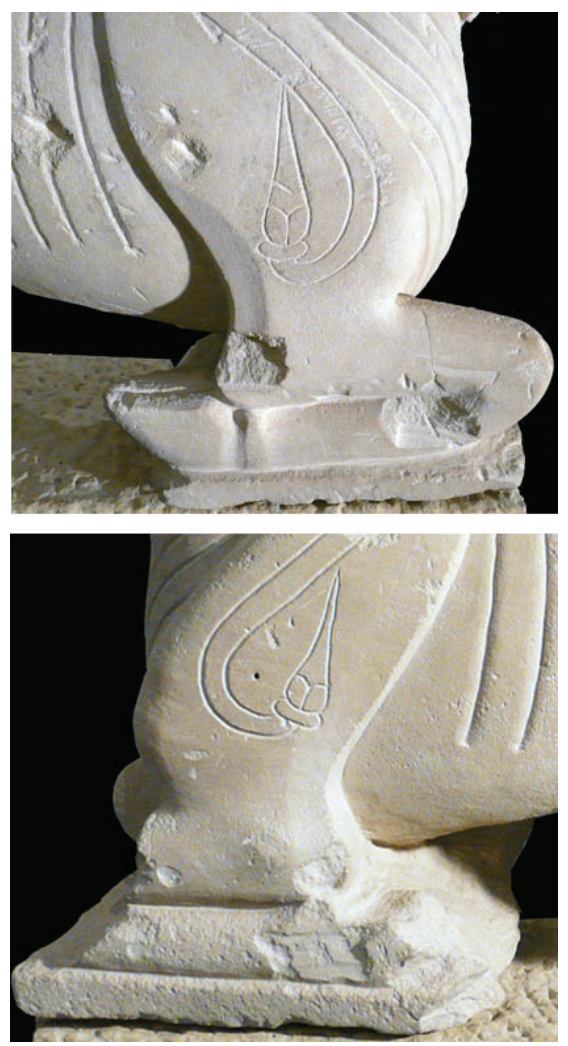

Figura 19.- "Cajas" preparadas a la altura de los codos para incluir apliques rectangulares.

cretos, en los que la pieza iría revestida de signos religiosos de lujo, mientras que el resto del tiempo éstos se retirarían. También puede proponerse que estos elementos no se concibieron en el momento de realización de la escultura, sino que fue enriquecida más tarde con ellos

\section{Contexto cultural e iconográfico}

Los rasgos formales del "torito" de Porcuna son suficientemente explícitos como para considerarlo una obra de tipo orientalizante. Las primeras valoraciones que de ella se hicieron carecían de información que avalara la presencia de este contexto cultural en el área de la Campiña giennense, pero en la actualidad hay datos suficientes para documentar esta etapa, evidenciando su importancia no solo en Andalucía occidental, sino en todo el pasillo de conexión con el Alto Guadalquivir, donde constituye la fase inmediatamente anterior al primer desarrollo ibérico. En consonancia con esto, los distintos autores han ido remontando progresivamente la cronología de esta pieza hasta situarla en este contexto. García y Bellido (1980: 69-70) lo fechaba en 
el tránsito entre el s. V y el IV a.C., siguiendo la primera opinión de Blanco (1960: 37-40). Estas primeras propuestas estaban condicionadas por la falta de elementos de referencia cronológica que caracterizó el estudio de la escultura ibérica al menos hasta la década de 1970, así como por la consideración de que la influencia griega era un factor sine qua non para el desarrollo de la estatuaria indígena, que por tanto no podía ser anterior al s. VI a.C.

El hallazgo de contextos arqueológicos claros para ciertos conjuntos, como los de Cigarralejo (Cuadrado 1984), Pozo Moro (Almagro-Gorbea 1983) o Baza (Presedo 1982), unido al hallazgo crucial de las esculturas de Cerrillo Blanco de Porcuna (González Navarrete y Arteaga 1980), datadas estilística y arqueológicamente en el s. V a.C. (Negueruela 1990: 303), aportaron nuevas posiciones de referencia para la valoración del "torito". Chapa (1980: 829-831) lo relacionó con modelos orientales, y propuso una fecha de la segunda mitad del s. VI a.C., vinculándolo al nacimiento de los primeros territorios políticos ibéricos constatados para esta etapa (Chapa 1996: 69-70). Por su parte, volviendo a los argumentos estilísticos, Rouillard (1998: 237) propuso su pertenencia a fines del s. VI o inicios del V a.C., mientras que León (1998: 81) prefiere la primera de estas opciones. Más radical fue el propio Blanco (1987: 35) quien, a la luz de todos los datos, afirmó sobre el toro: "lo tengo hoy por obra muy antigua, quizá de principios del s. VI a.C.".

Como acabamos de indicar, la presencia griega en las costas mediterráneas se consideraba una condición necesaria para el traslado a la piedra de una iconografía que por otro lado era estrictamente orientalizante. Sin embargo, nuevos hallazgos en el entorno de los asentamientos fenicios, como Puente de Noy y la revalorización de otros como los de Villaricos (ver panorama general en Almagro-Gorbea y Torres 2010), abrieron la puerta para considerar que el nacimiento de la escultura en piedra pudo producirse antes de la presencia sistemática de los griegos en las costas peninsulares, vinculándose a contextos coloniales fenicios y al entorno que en líneas generales podemos llamar tartésico. La escultura del "guerrero" de Cádiz (Belén y Chapa e.p.) o el fragmento de estatua femenina de Carmona (Belén y García Morillo 2005) son buenos referentes en este sentido. Liberada del "freno cronológico" ligado a la presencia griega, buena parte de la escultura que García y Bellido (1980: 69) consideraba "de raigambre orientalizante", ha pasado a considerarse directamente perteneciente a este contexto, por lo que Almagro Gorbea y Torres (2010: 379) han calificado la figura de Porcuna como paradigma de la escultura "tartesio-ibérica", fechándola en el s. VII a.C.
Esta centuria, sobre todo en sus últimas décadas, parece adecuada para situar el momento de factura y empleo del "torito", puesto que este tipo de iconografía encaja bien con las características del poblamiento documentado arqueológicamente (Fig. 20). En el entorno inmediato, los trabajos del "Proyecto Porcuna" en el Cerro de Los Alcores detectaron en las fases V, VI y VII del corte 15 la presencia de casas de planta rectangular con subdivisiones internas, en cuyas paredes se documentaron restos ocasionales de pintura, así como suelos de tierra apisonada, coloreados de rojo. El último de estos niveles (VII) incluye además la presencia de cerámica pintada con motivos figurativos similar a la de otros yacimientos como Carmona o Montemolín. Uno de los fragmentos mostraba una figura "de apariencia femenina, con el torso de frente, la cabeza de perfil y el ojo dispuesto igualmente de manera frontal, no dejando de ofrecer un aire egiptizante". Los investigadores fecharon estos niveles desde el s. VII a la primera mitad del s. VI a.C. (Arteaga 1985: 284).

De época orientalizante es también la necrópolis que se instala en Cerrillo Blanco (González Navarrete y Arteaga 1980; Torrecillas González 1985) y

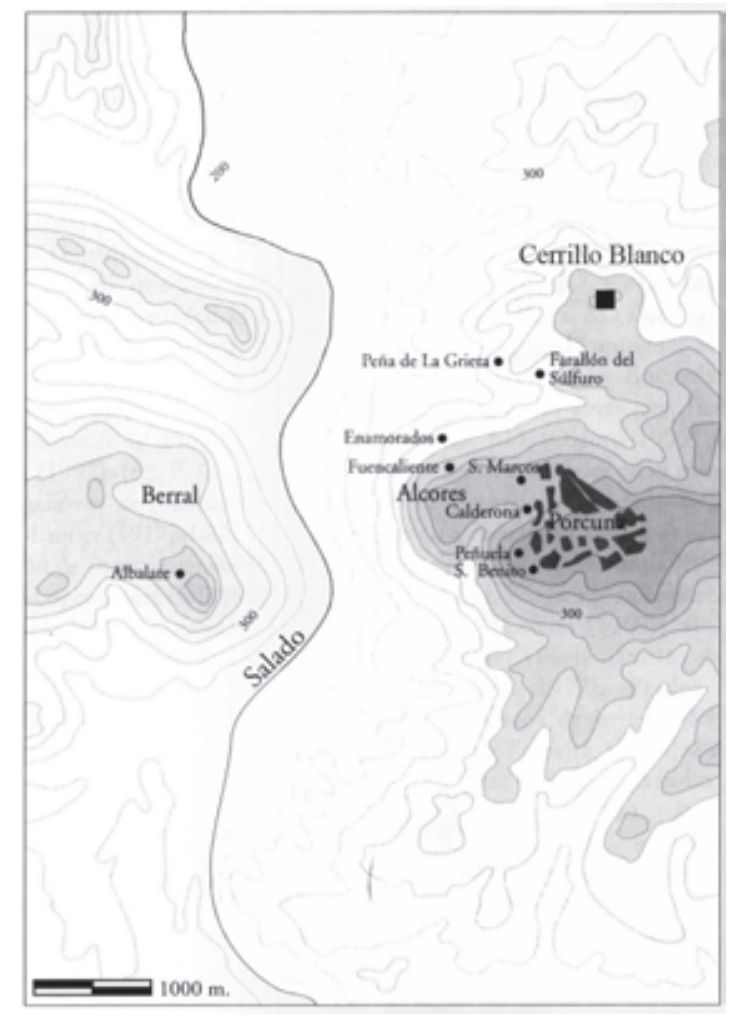

Figura 20.- Localización de los principales yacimientos de Porcuna: Alcores, Albalate, Cerrillo Blanco y el propio casco urbano (A partir de Arteaga 1999, fig. 2). 

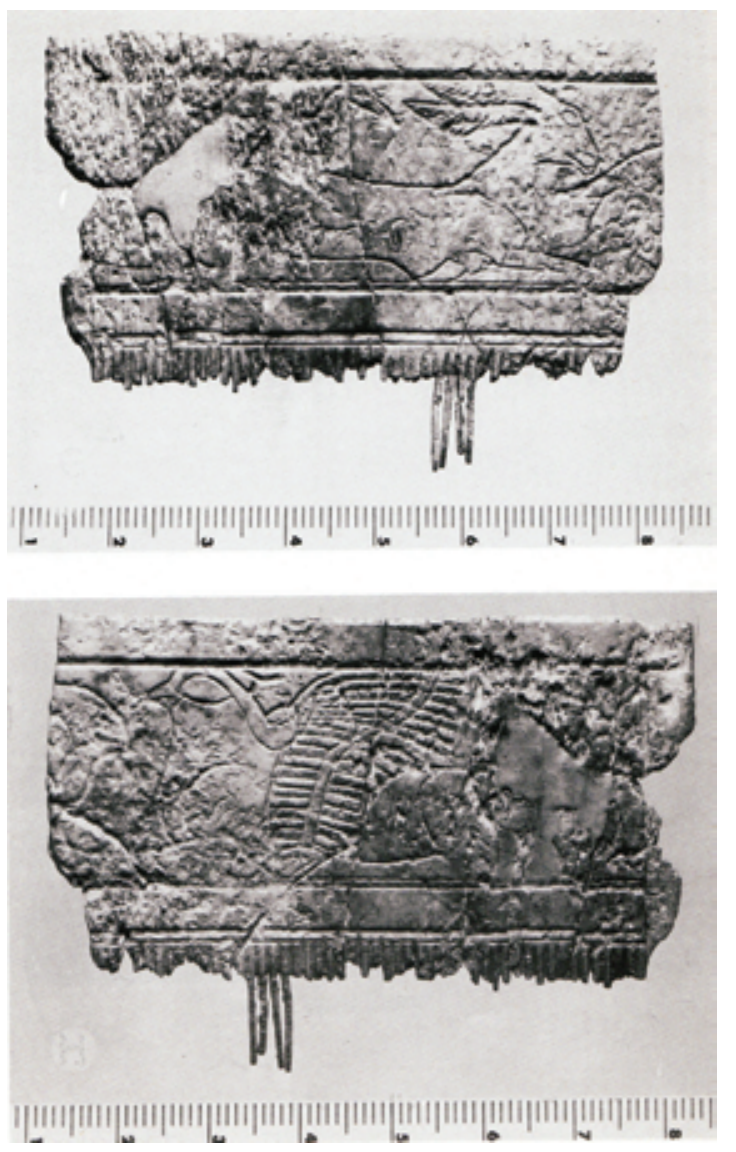

Figura 21.- Peine hallado en la tumba 14 de la necrópolis orientalizante de Cerrillo Blanco (a partir de Torrecillas 1985: 135).

de la que se pudieron excavar 24 tumbas individuales de inhumación y una doble, cuya estructura era más compleja. Los escasos objetos de ajuar corresponden en general a elementos relacionados con la vestimenta (peine, fíbulas, broches de cinturón), a lo que puede sumarse algún cuchillo de hierro de hoja curva o unas "pinzas de depilar" de bronce. La única representación iconográfica en este contexto corresponde a un peine de hueso o marfil, en cuya placa, incompleta, se aprecian una liebre echada de largas orejas que sigue a otra representación no definible, y un grifo también echado, cuya ala surge de la parte trasera del hombro izquierdo. Delante de su pico se aprecia una gran flor (Fig. 21). Aunque sin identidades exactas, esta pieza no desentona de las recuperadas en contextos más occidentales, como Osuna o Cruz del Negro en contextos del s. VII a.C. (González Navarrete y Arteaga 1980: 195). Si bien la riqueza de los ajuares es muy limitada, la posición estratégica del cerro en relación a caminos y fuentes de agua, así como la localización en este punto de las esculturas correspondientes al s. V a.C., hacen pensar que este grupo tuvo una considerable relevancia social. En todo caso, el exiguo número de personas enterradas lleva a suponer la existencia de otros cerros o túmulos en el entorno de Porcuna en donde también se practicaran enterramientos.

Por su parte, la cerámica con motivos figurativos recuperada en Los Alcores muestra el empleo habitual de temas antropomorfos, zoomorfos y florales en espacios que debieron tener un sentido religioso, y que Arteaga (1985: 284) fechó desde finales del s. VII a la primera mitad del VI a.C. Esto nos lleva a relacionar también estos soportes iconográficos con los encontrados en santuarios como el de Montemolín, en el que se representan figuras de toros esquemáticos (Fig. 22), con cuerpos adelgazados y motivos geométricos decorando el cuerpo. La distribución de este tipo de cerámica está muy extendida desde Porcuna hacia el curso bajo del Guadalquivir, y aparece en todos sus afluentes por el sur (Chaves y de la Bandera 1986; Chaves et al. 1993: fig. 1).

Desde el punto de vista iconográfico, ya se ha señalado que el diseño corporal y algunos rasgos anatómicos del "torito" tienen sus paralelos más próximos en las esculturas de leones cordobeses. Comparte con ellos el marcado adelgazamiento del vientre hacia los cuartos traseros, vaciando la parte inferior del bloque pétreo, y especialmente las orejas, que podrían corresponder a cualquiera de estos felinos, e incluso también a los de Pozo Moro (Almagro Gorbea y Torres, 2010: 378) o a las cabecitas en bronce de la necrópolis de La Joya (Garrido y Orta, 1978: 169-170). En definitiva, las orejas acercan al toro de Porcuna a la iconografía del león, mientras que resultan totalmente excepcionales en el contexto de los bóvidos, que buscan separarlas de la cabeza y darles una morfología más acorde con la realidad. El torito en bronce del Cerro del Prado (Ulreich et al., 1990) sería el paralelo más cercano, aunque en este caso las orejas tampoco se adhieren al cuello.(Fig. 22)

Sin embargo, otros aspectos del bóvido de Porcuna que aparentemente también podrían ligarse al mundo de los felinos, como la representación del costillar mediante líneas paralelas verticales, no coinciden con los leones que pudieran ser contemporáneos -series de Nueva Carteya, Baena o Santaella-, puesto que éstos no las tienen. En este sentido, el de Porcuna se vuelve a acercar a modelos fabricados en marfil o cerámica, como puede apreciarse en la reciente síntesis de Le Meaux (2010: 43-47). Además del ejemplo de Montemolín ya citado, los toros de los marfiles de Bencarrón o Cruz del Negro (Aubet 1979: fig 4; Aubet 1981-1982, fig. 2) tienen indicadas las costillas, un elemento común en este caso a carnívoros y herbívoros. No debemos olvidar que, como en otros contextos medite- 

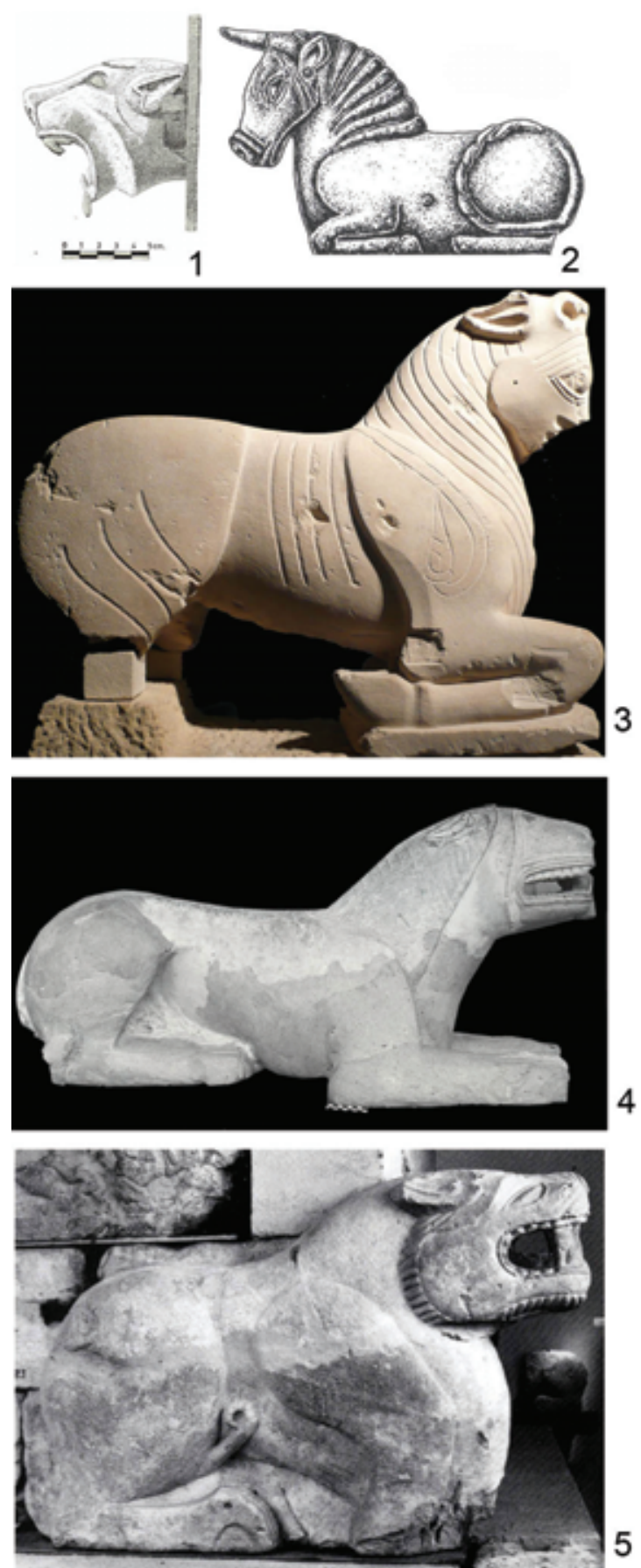

Figura 22.- Cubo de carro con cabeza de león de La Joya, Huelva (a partir de Garrido y Orta 1978); 2. Toro de bronce de El Prado (a partir de Jiménez Ávila 2001, Lam. LII); 3. Torito de Porcuna; 4. León de Nueva Carteya, Córdoba (Foto: T. Chapa); 5. León de Pozo Moro, Albacete (a partir de Almagro-Gorbea 1983, Lam. 18b).

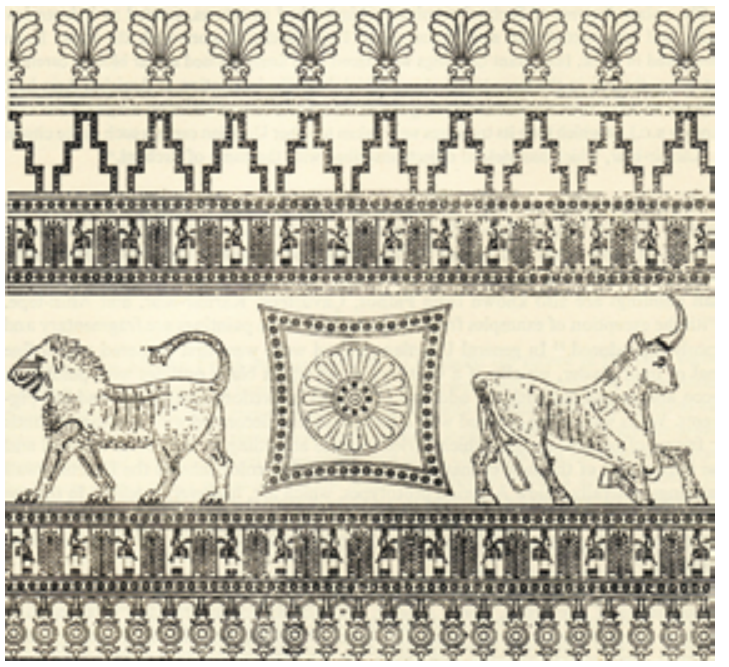

Figura 23.- Pinturas del palacio de Arin-Berd (Erebuni, Urartu), primera mitad del s. VIII a.C. (a partir de Azarpay 1968: 19).

rráneos, existieron muchos otros soportes a los que se asociaban estas representaciones iconográficas, como telas, muebles o superficies pintadas, que no han llegado hasta nosotros. De hecho, los paralelos formales más próximos al "torito" son los bóvidos jóvenes que decoraban los palacios y santuarios del área urartea, que tienen el costillar indicado y flanquean por parejas la roseta solar enmarcada en un rectángulo de lados cóncavos (Fig. 23) La influencia de Urartu en ciertas producciones mediterráneas del primer milenio ha sido comentada en otro lugar (Chapa 2005: 37).

En cuanto a las tres líneas curvas que se sitúan sobre los dos muslos, pueden relacionarse con las marcas que están presentes en los animales, tanto carnívoros como herbívoros, representados en los marfiles del suroeste y en las cerámicas orientalizantes con tema zoomorfo. Su origen debe estar en el tema denominado "flame and frond" (AlmagroGorbea 2008: 411), del que es una simplificación, ya que las incisiones no se cierran en la parte superior formando las "llamas", salvo que el tema se completara mediante pintura (Fig. 24).

Precisamente en este sentido cabe preguntarse si la estatua tendría el color blanco actual o si estaría coloreada total o parcialmente. La conservación excepcional de la Dama de Baza, con un uso rico y variado del color tanto en el cuerpo como en la vestimenta (Gómez et al. 2010), así como la aplicación de técnicas analíticas y de imagen en diversos conjuntos escultóricos mediterráneos (Brinkmann 2009) ha recuperado la noción del color como uno de los elementos fundamentales de la manufactura escultórica. En el entorno cronológico y geográfico 

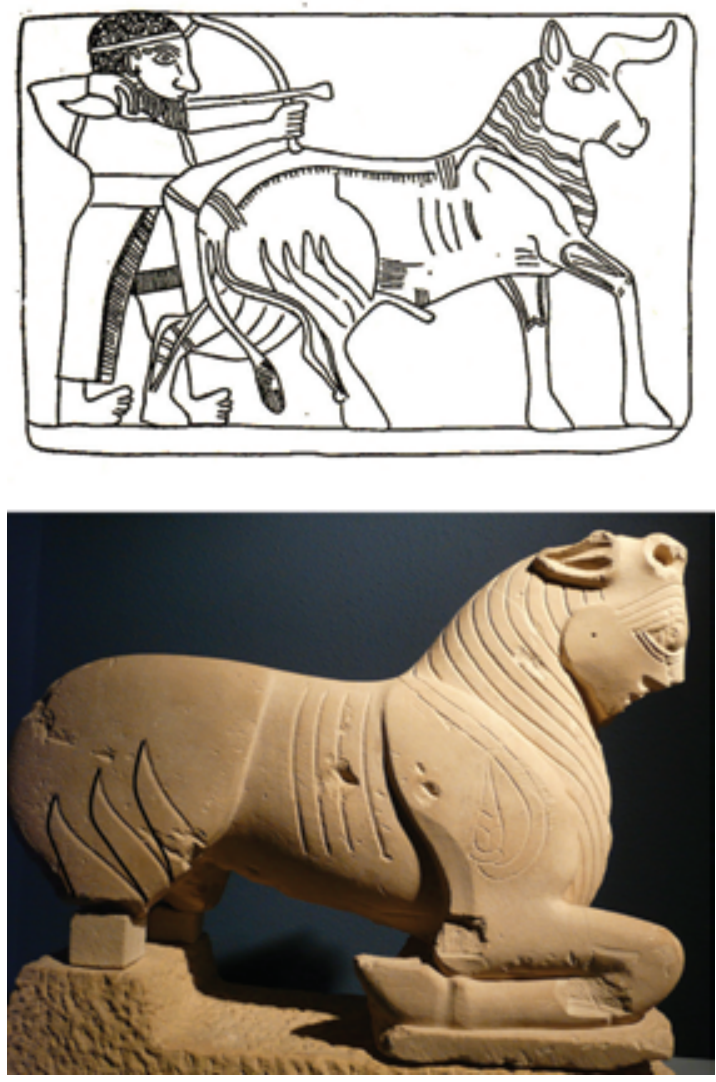

Figura 24.- Arriba: Ortostato de Tell Halaf con escena de caza de un toro en el que se han marcado las costillas y las incisiones "flame and frond" de los cuartos traseros, segunda mitad del s. VIII a.C. (a partir de Akurgal 1969, fig. 88). Abajo: efecto "flame and frond" en el torito de Porcuna añadiendo líneas pintadas.

del "torito" sólo tenemos evidencia visible de pintura roja en la leona del Cerro de la Mitra de Santaella (Palma Rodríguez et al. 1996: 4). En el caso de Porcuna, la aplicación de luz ultravioleta no ha dado resultados, aunque podrían aplicarse otros métodos alternativos (Mielke e.p.). Sin embargo, la proximidad de la figura a las representaciones sobre marfil, y la importante presencia de elementos accesorios permite suponer que éstos proporcionarían un contraste de color suficiente respecto a la tonalidad natural de la piedra.

\section{Hipótesis sobre el monumento al que corres- pondería la escultura}

Por el momento, resulta muy difícil hacer una propuesta bien fundamentada sobre la reconstrucción del espacio en el que se insertaría el "torito". Como se ha dicho, es una escultura con rasgos únicos y por otro, como tantas otras, ha aparecido fuera de contexto. Por tanto, nos basaremos en apreciaciones derivadas de la observación de esta y otras piezas paralelas, con la intención de realizar algunas propuestas razonables cuya confirmación tendremos que dejar para un futuro, esperemos que no demasiado lejano.

En primer lugar, y aunque sabemos que no puede descartarse una atribución funeraria, manejaremos preferentemente la hipótesis de que se trataba de una estatua vinculada al culto. Es cierto que la ausencia de noticias sobre la existencia de huesos o cenizas en el momento de su hallazgo no puede tomarse como un dato definitivo, dadas las circunstancias del momento. También es verdad que si se hubieran encontrado, algo habría trascendido en la población, teniendo en cuenta la sensibilidad que sobre los enterramientos humanos fuera de los cementerios existía en la época de la postguerra civil. En todo caso, nuevas construcciones en la zona donde se recuperó la escultura no han llamado la atención sobre este hecho.

Su posición, en la entrada a Porcuna desde Arjona-Alharilla, hace pensar en que el hipotético santuario sería paso obligado para los que entraran o salieran de la población por este camino. En este sentido, cabe resaltar la similitud del lugar con la del hallazgo del toro de Arjona. Aunque en la publicación derivada de su donación al Museo de Granada se decía que apareció en una finca, los datos confirman que se encontró en la actual calle de Juan Talero, que durante muchos años se llamó por esta causa "calle del Toro". También las noticias de Martínez Ramos (1944-1945) indican que su descubrimiento se produjo en la propia ciudad. Cabe pensar, por tanto, que en las zonas urbanas existieron santuarios para los que se tallaron algunas de las primeras esculturas zoomorfas en piedra.

Teniendo en cuenta sus características formales, el toro debía estar sobre un pilar, a una altura no mayor de 1,75-2 m. Desde esta altura las partes menos trabajadas quedarían ocultas, tomando importancia otras menos observables, como la suave silueta de los genitales sobre la línea de las patas traseras, lo que explica la fuerte estilización del vientre en esta zona. La visualización de la escultura favorece la perspectiva frontal e izquierda, donde están los apliques laterales y el final del rabo. Sin embargo, si existiera un armazón decorativo sería difícil diferenciar el lado preferente. En todo caso, la perspectiva menos correcta es la trasera, puesto que se aprecia en ella una incorrección anatómica en el nacimiento del rabo

Dentro de este hipotético espacio sagrado, podemos considerar que el "torito" fue una pieza única, en cuyo caso remataría un pilar del que no se ha 
recuperado ningún componente. Su posición, en una de las entradas a la ciudad, marcaría una posición de especial significación religiosa, en la que el animal simbolizaría a la divinidad protectora de la población. Existirían probablemente elementos dedicados al culto y a la recepción de ofrendas, que se practicarían antes de la entrada en el asentamiento. Aunque la escultura debió de estar protegida por una techumbre, dados los escasos vestigios erosivos que presenta su superficie, es difícil imaginar razonadamente cuáles serían las características de esta estructura.

Sin embargo, cabe plantear también la posibilidad de que esta figura formara parte de un conjunto de carácter sacro. Esta hipótesis se basa sobre todo en la ruptura de la frontalidad de la cabeza, girada levemente a la derecha, mientras que elementos importantes del lado izquierdo del cuerpo, como los orificios del brazo y muslo, o la presencia del final del rabo harían pensar en una visión lateral preferente por este costado. En este caso podría existir un segundo ejemplar complementario, flanqueando la puerta del espacio de culto, o bien a una representación divina. Consideramos que esta divinidad pudo ser femenina, teniendo en cuenta los atributos florales del "torito", ligados especialmente a diosas como Astarté, y la escasa insistencia en la representación tanto de rasgos agresivos como de los atributos sexuales, al contrario de lo que sucede en los toros del área mediterránea o en los más cercanos de La Victoria, Santa Sofía-El Polvillo o Santaella, todos ellos en Córdoba (Vaquerizo 1999; Morena 2004). Los dos últimos casos muestran una preferencia clara por su visualización desde uno de sus lados, lo que permite pensar en la existencia de una pareja, más probable en el caso de Santaella (Chapa 1986: 138, ver, en contra, Sanmartí 1987: 269).

\section{Conclusiones}

Lo dicho hasta ahora permite comprender a través de esta pieza la altísima y especializada dimensión iconográfica desarrollada por el mundo orientalizante en la Campiña giennense. Hemos planteado la posibilidad de que el "torito" sea por ahora el único testimonio de un lugar de culto situado en el área de entrada y salida de la antigua población por esta zona, aunque la falta de información sobre su contexto no nos permite afinar más en este sentido. Las excavaciones realizadas por el "Proyecto Porcuna" han confirmado, como hemos visto, la existencia de una importante organización urbanística durante los s. VII y VI a.C. en el Cerro de los Alcores, mientras que el vecino Cerro del Albalate se abandona (Arteaga 1999: 110). De la elevación que ocupa la
Porcuna actual se conocen mejor los restos de época ibérica tardía y romana, aunque no se descarta que existan niveles anteriores. Al fin y al cabo, en Los Alcores las estructuras de época orientalizante se sitúan a $3 \mathrm{~m}$ de profundidad y solo una excavación sistemática ha podido documentar la estratigrafía completa, que alcanza hasta la Edad del Cobre, y lo mismo podría suceder en Porcuna.

La posible existencia de un santuario que albergara al "torito" no sólo tiene sentido en el marco de un espacio límite, sino también en el hecho de tratarse de un emplazamiento en altura. Muy cerca de su zona de aparición se sitúa precisamente el punto más alto de toda el área directamente relacionada con Porcuna (490 m s.n.m.), siendo 397 $\mathrm{m}$ la altura del Cerro del Albalate y $422 \mathrm{~m}$ la cota máxima de Los Alcores. La visibilidad fue sin duda un aspecto a tener en cuenta en el emplazamiento de los santuarios de la época, tanto en relación con la navegación como con el tránsito interior (Marín 2010: 506).

Se nos presenta, por tanto, un panorama en el que las sociedades de la Campiña, que han pasado por un proceso de agrupamiento poblacional en beneficio de las élites que capitalizan las riquezas basadas en el dominio de la tierra y de los medios de producción, se muestran como representantes colectivos del grupo social. Esta nueva situación está fuertemente relacionada con la estructura política que diversos autores (Molinos et al. 1995; Arteaga 1999: 112) vinculan al mundo tartésico occidental, del que Porcuna sería una de sus poblaciones límites, como también lo serían Arjona y Los Villares de Andújar. La presencia del "torito", tan ajustado en su concepción y expresión iconográfica a esos modelos, junto a la presencia de cerámicas decoradas y otros elementos materiales, nos indica que en la ciudad de Porcuna se adoptaron formas de vida, creencias, ritos y expresiones religiosas propiamente orientalizantes. A este contexto, situado en la segunda mitad del s. VII o muy inicios del s. VI a.C. debemos ligar la escultura del "torito", interpretado como imagen o elemento asociado a una divinidad femenina con rasgos próximos a Astarté.

Es importante resaltar que la escultura no sólo debe ser contemplada desde un punto de vista iconográfico, por más que este enfoque aporte una información fundamental. El proceso de manufactura del "torito" nos ha revelado el alto nivel técnico y creativo contenido en esta pieza, y por tanto la presencia de un equipo de especialistas dirigidos por un escultor con excelentes cualidades artísticas. Bajo su dirección trabajaron tanto canteros como otros ayudantes, demostrando importantes conocimientos sobre todo el proceso de la obra y el manejo de instrumental especializado, a lo que hay 
que añadir el trabajo de creación y engaste de los elementos accesorios y la colocación de la imagen en un espacio adecuado. Aunque situemos la figura del escultor y su equipo en un marco dependiente de la autoridad, su demostrada capacidad artística y técnica, así como el tiempo y el material invertido en la realización de la figura, debieron suponer una inversión económica muy importante. La religión y sus manifestaciones, el "mundo de las apariencias" en palabras de Ruiz y Sánchez (2003: 140), a través del que afloran tantos aspectos materiales, nos indica que la implantación de una nueva iconografía religiosa fue uno de los aspectos fundamentales asociados al desarrollo de las nuevas aristocracias locales, cuyas fórmulas expresivas se aproximan significativamente al universo inicialmente introducido por la presencia fenicia.

Aunque este contexto cultural declina a lo largo del s. VI a.C. hasta desaparecer, puede decirse que provoca un uso continuado de la escultura en piedra como recurso expresivo en el núcleo de Porcuna. De hecho, y al contrario que las posteriores y también excepcionales figuras "enterradas" en la fosa de Cerrillo Blanco (Negueruela 1990), esta pieza sufrió unos daños limitados cuando dejó de emplearse. Es cierto que presenta algunas fracturas que hemos puesto en relación con el arranque de las piezas accesorias de valor repartidas por diversas zo- nas de su cuerpo. Además de esto, y dado que debió estar situada a cierta altura, un derribo intencionado con ayuda de cuerdas pudo provocar la fractura de las patas de atrás y del hocico. En este último caso, los intentos de romper experimentalmente esta zona mediante puntero o cincel en la réplica trabajada en el taller de Porcuna no consiguieron el mismo efecto que presenta la pieza original, por lo que la hipótesis de la caída se mantiene. Sin embargo, una vez en el suelo y habiéndole arrancado sus elementos accesorios, la escultura no sufrió más daños. Es notable el hecho de que tanto los bóvidos de cuernos y orejas postizos de la zona mediterránea, como el conjunto de bóvidos y leones del área cordobesa, presentan un estado de conservación comparativamente mejor que el de la restante estatuaria ibérica en piedra, como si a pesar de dejar de estar en uso se hubiera respetado su integridad.

El toro echado de Porcuna tiene su contexto iconográfico en el área cordobesa, aunque ninguno de los bóvidos o leones de esa zona llega a mostrar unos rasgos tan finos y exquisitos. Antes de que Cerrillo Blanco se convirtiera en un referente primordial para la escultura ibérica, la etapa orientalizante produjo en Porcuna al menos una pieza que cabe situar también en el nivel más alto de la iconografía en piedra andaluza, mostrando claramente la importancia económica y religiosa de la antigua Ipolca.

\section{Agradecimientos}

Son muchas las personas e instituciones que nos han ayudado a realizar este trabajo. Francisco Javier Pajares Gutiérrez, hijo de Ramón Pajares Pardo, nos ha proporcionado información sobre el momento en el que su padre recibió la escultura y cuando posteriormente decidió donarla. El estudio del proceso de trabajo ha contado con el asesoramiento de Francisco Aguilera, cantero y escultor de Porcuna y heredero de una larga saga de especialistas, que conoce a fondo todo lo relacionado con la piedra y su talla. Sonia Flores y David Vincent, del Centro Tecnológico Andaluz de la Piedra (Macael) hicieron el escaneado 3D de la escultura en el Museo de Jaén, en donde tanto su directora Francisca Hornos como la conservadora Margarita Sánchez Latorre dieron todas las facilidades para llevar a cabo el trabajo.

El estudio iconográfico ha contado con el apoyo de Alberto Herrero, investigador científico del Real Jardín Botánico (CSIC) para la determinación de la flor representada sobre el toro. J. Alvarez Mon, de la Universidad de Sydney, ha aportado certeras apreciaciones sobre diversos elementos decorativos de la escultura. A. Perea e I. Montero, del Centro de Ciencias Humanas y Sociales (CSIC) nos han informado sobre la idoneidad de los posibles elementos metálicos añadidos. La referencia a la situación del toro de Arjona se debe a José Puentes, alcalde de esa población en el momento de redactar este trabajo, y al cronista oficial de la ciudad, Manuel Antonio Cardeña Perales. Finalmente, queremos agradecer muy sinceramente el trabajo de revisión efectuado por dos evaluadores anónimos, que han ayudado mucho a la mejora de este texto.

\section{Notas}

1. Este artículo ha sido realizado en el marco del Proyecto HUM 2007/60074: "Escultura Ibérica: estudio iconográfico, tecnológico e historiográfico", financiado por el Ministerio de Ciencia e Innovación.

2. La ficha puede consultarse en el catálogo en red del Ministerio de Cultura (CERES) introduciendo como términos de búsqueda "toro de Porcuna": http://ceres.mcu.es/pages/Main y en el Portal de Museos de Andalucía: http://www.juntadeandalucia.es/cultura/museos/MJA/index.jsp?redirect=S2_3_1_1.jsp\&idpieza=843\&pagina=1 


\section{REFERENCIAS BIBLIOGRÁFICAS}

Akurgal, E. (1969): Orient et Occident. Albin Michel, Paris.

Almagro-Gorbea, M. (1983): Pozo Moro. El monumento orientalizante, su contexto socio-cultural y sus paralelos en la arquitectura funeraria ibérica. Madrider Mitteilungen, 24: 177-392.

Almagro-Gorbea, M. (2008): Objetos de marfil y hueso. La necrópolis de Medellín II. Estudio de los hallazgos (M. Almagro-Gorbea, dir.), Bibliotheca Archaeologica Hispana 26-2, Real Academia de la Historia, Madrid: 401-512.

Almagro-Gorbea, M.; Torres Ortiz M. (2010): La escultura Fenicia en Hispania. Bibliotheca Praehistorica Hispana 32, Real Academia de la Historia, Madrid.

Amores Carredano, F.; Escacena Carrasco, J. L. (2003): De toros y de tesoros: simbología y función de las joyas de El Carambolo. Fiestas de toros y sociedad (A. García Baquero González y P. Romero de Solís, eds.), Fundación Real Maestranza de Sevilla, Universidad de Sevilla, Fundación de Estudios Taurinos, Sevilla: 41-68.

Arboledas Martínez, L. (2010): La explotación masiva de los recursos mineros de Sierra Morena oriental: la minería iberorromana. La minería y la metalurgia en el Alto Guadalquivir: desde sus orígenes hasta nuestros días (F. Contreras Cortés y J. Dueñas Molina, J., eds.), Instituto de Estudios Giennenses, Diputación de Jaén, Jaén: 123-201.

Arteaga, O. (1985): Excavaciones arqueológicas sistemáticas en el cerro de Los Alcores (Porcuna, Jaén). Informe preliminar sobre la campaña de 1985. Anuario Arqueológico de Andalucía II. Actividades Sistemáticas 1985: 279-288.

Arteaga, O. (1999): La delimitación del territorio entre Cástulo y Obulco. De las sociedades agricolas a la Hispania romana (V. Salvatierra y C. Rísquez, eds.), Jornadas Históricas del Alto Guadalquivir (Quesada, 19921995), Universidad de Jaén, Jaén: 95-141.

Arteaga, O.; Nocete, F.; Ramos, J.; Roos, A. M. (1993): Reconstrucción del proceso histórico en la ciudad ibero-romana de Obulco. El Proyecto Porcuna (Jaén). Investigaciones Arqueológicas en Andalucía. 1985-1992, Huelva: 809-814.

Aubet, M.E. (1979): Marfiles fenicios del bajo Guadalquivivir. I. Cruz del Negro. Studia Archaeologica 52, Seminario de arqueología, Facultad de Filosofía y Letras, Universidad de Valladolid.

Aubet, M. E. (1981-1982): Marfiles fenicios del Bajo Guadalquivir (y III). Bencarrón, Santa Lucía y Setefilla. Pyrenae, 17-18: 33-92.

Azarpay, G. (1968): Urartian art and artifacts. A chronological study. University of California Press, Berkeley y Los Angeles.

Belén, M.; Anglada, R.; Escacena, J. L.; JimÉnez, A.; Lineros, R.; Rodríguez, I. (1997): Arqueología en Carmona (Sevilla). Excavaciones en la casa-palacio del Marqués de Saltillo. Consejería de Cultura de la Junta de Andalucía, Colección Arqueología, Sevilla.

Belén, M.; García Morillo, M. C. (2005): Carmona. Una ciudad tartésica con estatuas. El Periodo Orientalizante. Vol. II. Actas del III Symposio Internacional de Arqueología de Mérida: Protohistoria del Mediterráneo Occidental (S. Celestino Pérez y J. Jiménez Ávila eds), Anejos de Archivo Espańol de Arqueología XXXV, Consejo Superior de Investigaciones Científicas, Mérida: 1199-1213.

Belén, M.; Marín Ceballos, M. C. (2002): Diosas y leones en el periodo orientalizante de la Península Ibérica. SPAL, 11: 169-195.

Belén, M.; Chapa, T. (en prensa): Der "Krieger" von Cádiz und die Steinskulptur im phönizischen Kontext der Iberischen Halbinsel. Madrider Mitteilungen.

BeltrÁn, J.; Loza, M. L. (2005): El "Oso de Porcuna”. Una escultura funeraria excepcional de la Hispania romana. Romula, 4: 163-176.

Blanco Freijeiro, A. (1960): Orientalia II. Archivo Español de Arqueología, 33: 1-43.

Blanco Freijeiro, A. (1961-1962): El toro ibérico. Homenaje al Prof. C. de Mergelina, Murcia: 163-195.

Blanco Freijeiro, A. (1987): La escultura ibérica. Una interpretación. Escultura Ibérica (García Castro, J.A., dir.), Revista de Arqueología (número monográfico), Ed. Zugarto, Madrid: 32-47.

Blánquez, J.J. (ed) (2003): Cerámicas orientalizantes del Museo de Cabra. Ayuntamiento de Cabra, Madrid.

BRINKMANN, V. (2009): La investigación sobre la policromía de la escultura en la Antigüedad. Introducción a la exposición. El color de los dioses, Catálogo de la Exposición, Museo Arqueológico Regional (18-diciembre 2009 a 18 de abril 2010), Madrid: 21-32. 
Cazabán, A. (1927:) La escultura hallada en Porcuna. Don Lope de Sosa, 177: 271-273.

Chapa Brunet, T. (1980): La Escultura Zoomorfa Ibérica. 2 vols. Universidad Complutense de Madrid, Madrid.

Chapa Brunet, T. (1986): Influjos griegos en la escultura zoomorfa ibérica. Iberia Graeca, Serie Arqueologica ${ }^{\circ}$ 2, CSIC, Madrid.

Chapa Brunet, T. (1996): El nacimiento de la escultura funeraria ibérica. Formes Archaiques et Arts Ibèriques (R. Olmos y P. Rouillard, eds), Collection de la Casa de Velázquez 59, Madrid: 67-82.

Chapa Brunet, T. (2005): Las primeras manifestaciones escultóricas ibéricas en el oriente peninsular. Archivo Español de Arqueología, 78: 23-47.

ChAPA BRUNET, T. (2005-2006): Iconografía y economía: un ejemplo aplicado a los orígenes de la escultura ibérica en el área del Bajo Segura (Alicante). Homenaje a Jesús Altuna, vol. III, Munibe, 57: 243-256.

Chaves, F.; de la Bandera, M. L.; Ferrer, E.; Bernáldez, E. (2000): El complejo sacrificial de Montemolín. Actas del IV Congreso Internacional de Estudios Fenicios y Púnicos. Universidad de Cádiz, Vol. II, Cádiz: 573-581.

Chaves, F.; DE la Bandera, M. L. (1986): Figürlich Verzierte Keramik aus dem Guadalquivir-Gebiet. Die Funde von Montemolín (bei Marchena, Prov. Sevilla). Madrider Mitteilungen, 27: 117-150 (láms. 16-18).

Chaves, F.; de la Bandera, M. L.; García Vargas, E.; Ferrer Albelda, E.; Oria Segura, M. (1993): Investigación arqueológica en Montemolín. Investigaciones Arqueológicas en Andalucía 1985-1992. Proyectos. Junta de Andalucía, Huelva: 501-513.

Cuadrado, E. (1984): Restos monumentales funerarios de El Cigarralejo. Trabajos de Prehistoria, 41: 251-290.

Donohue, A. A. (1988): Xoana and the origins of Greek Sculpture. Scholars Press, American Classical Studies 15 , Atlanta.

Escalera Ureña, A. (1978): Examen de laboratorio de los materiales de "La Joya" (Huelva). Excavaciones en la Necrópolis de La Joya. Huelva. II (J.P. Garrido y E. Orta, eds.), Excavaciones Arqueológicas en España 96, Ministerio de Cultura, Madrid: 213-256.

García Bellido, A. (1943): De escultura ibérica. Algunos problemas de arte y cronología. Archivo Español de Arqueología, XVI: 272-299.

García y Bellido, A. (1960): Inventario de jarros púnico-tartéssicos. Archivo Español de Arqueología, XXXIII: 44-63.

García y Bellido, A. (1980): Arte Ibérico en España. Espasa Calpe, Madrid.

García Gandía, J. R. (2009): La Necrópolis Orientalizante de Les Casetes (La Vila Joiosa, Alicante). Serie Arqueológica, Anejos de Lucentum 19, Publicaciones de la Universidad de Alicante, Alicante.

GARRIDO, J. P. y ORTA, E. (1978): Excavaciones en la Necrópolis de La Joya. Huelva. II. Excavaciones Arqueológicas en España 96, Ministerio de Cultura, Madrid.

Gómez, M.; Navarro, J. V.; Martín de Hijas, C.; del Egido, M.; Algueró, M.; GonzÁlez, E.; Arteaga, Á. (2010): La escultura de Baza: materias, pátinas y policromía. La Dama de Baza. Un viaje femenino al más allá (T. Chapa e I. Izquierdo, coords.), Actas del Encuentro Internacional (Museo Arqueológico Nacional, 27-28 de noviembre 2007), Ministerio de Cultura, Madrid: 103-117.

Gómez, M.; NAVARro, J. V.; Albar, A. (2011): El color en la escultura ibérica a la luz de los análisis físico-químicos: los ejemplos de Baza y Elche. ¿Hombres o dioses? Una nueva mirada a la escultura del mundo ibérico (J. Blánquez Pérez, ed.), Museo Arqueológico Regional, Madrid: 315-335.

Gómez Rendón, Á. (1998): Mapas geométricos. Análisis y aplicaciones especulativas. Padilla Libros, Sevilla.

González Navarrete, J. (1987): Escultura Ibérica de Cerrillo Blanco, Porcuna, Jaén. Diputación Provincial de Jaén, Instituto de Cultura, Jaén.

González Navarrete, J.; Arteaga, O. (1980): La necrópolis del Cerrillo Blanco y el poblado de Los Alcores (Porcuna, Jaén). Noticiario Arqueológico Hispánico, 10: 185-217.

Green, A. R. W. (2003): The Storm God in the Ancient Near East. Winona Lake, Ind. Eisenbrauns.

Izquierdo Peraile, I. (2000): Monumentos funerarios ibéricos: los pilares-estela. Diputación Provincial de Valencia. Servicio de Investigación Prehistórica, Serie de Trabajos Varios 98, Valencia

Jiménez Ávila, J. (2002): La toréutica orientalizante en la Península Ibérica. Bibliotheca Archaeologica Hispana 16, Real Academia de la Historia, Madrid.

Kielland, E. C. (1987): Geometry in Egyptian Art. Dreyers Forlag, Oslo.

Le Meaux, H. (2010): L'Iconographie Orientalisante de la Péninsule Ibérique. Questions de styles et d'Échanges (VIIIe-VIe siècles av. J.-C.). Casa de Velázquez, Madrid. 
LEÓN, P. (1998): La sculpture des Ibères. l'Harmattan, Paris.

Llobregat, E. A. (1974): El toro ibérico de Villajoyosa (Alicante). Zephyrus, XXV: 335-342.

Marín Ceballos, M. C. (2010): Imagen y culto de Astarté en la Península Ibérica I: Las fuentes griegas y latinas. El Carambolo. 50 años de un tesoro. (M.L. de la Bandera Romero y E. Ferrer Albelda, eds.), Secretariado de Publicaciones de la Universidad de Sevilla, Sevilla: 491-512.

Martínez Ramos, B. (1944-1945): Fundación de la ciudad de Arjona por los Iberos. Paisaje, I: 216-220.

Mata Parreño, C.; Badal García, E.; Bonet Rosado, H.; Collado Mataix, E.; Fabado Alós, F. J.; Izquierdo Peraile, I.; Moreno Martín, A.; Ntinou, M.; Quixal Santos, D.; Ripollés Alegre, P. P.; Soria Combadiera, L. (2010): De lo real a lo imaginario. Aproximación a la flora ibérica durante la Edad del Hierro. Anales de Arqueología Cordobesa, 18: 93-122.

Matz, F. (1960): La Crète et la Grèce Primitive. Prolégomenes de l'Art Grec. Albin Michel, Paris.

Mielke, D. 2011 (e.p.). Die Polychromie iberischer Skulpturen. Madrider Mitteilungen 52.

Molinos Molinos, M.; Ruiz Rodriguez, A.; Serrano Peńa, J. L. (1995): La frontera oriental de Tartessos. En Tartessos, 25 ańos después (1968-1993). Actas del Congreso Conmemorativo del V Symposium Internacional de Prehistoria Peninsular. Ayuntamiento. Jerez de la Frontera: 239-254.

Morena López, J. A. (2004): Tres nuevos bóvidos ibéricos en piedra procedentes del valle del Guadajoz (Córdoba). Romula, 3: 7-36.

Negueruela, I. (1990): Los monumentos escultóricos ibéricos del Cerrillo Blanco de Porcuna (Jaén). Ministerio de Cultura, Madrid.

Negueruela, I. (1992): La escultura ibérica. Cuadernos de Arte Español 57, Historia 16, Madrid: 1-31 (monográfico).

Olmos Romera, R. (dir.) (1999): Los Iberos y sus imágenes. CD-Rom. Micronet, Consejo Superior de Investigaciones Científicas, Madrid.

Olmos Romera, R. (2003): La imagen en la cultura tartésica. Cerámicas orientalizantes del Museo de Cabra (J.J. Blánquez, ed), Ayuntamiento de Cabra, Madrid: 32-55.

Palagia, O. (2006): Marble Carving Techniques. Greek Sculpture. Function, Materials and Techniques in the Archaic and Classical Periods (O. Palagia, ed). Cambidge University Press, Cambridge: 243-279.

Palma Rodríguez, J.; Palma Franquelo, J. M.; del Moral Aguilar, F. J. (1996): El tránsito hacia la Historia en Santaella. Singilis, Año II, nº 2. 1-6.

Patay-Horváth, A. (2009) Hair or Wreath? Metal Attachments on Marble Heads in Architectural Sculpture. Structure, Image Ornament: Architectural Sculpture in the Greek World (P. Schultz y R. von den Hoff, eds.). Proceedings of an international conference held at the American School of Classical Studies, 27-28 November 2004, Oxbow Books, Oxford and Oakville: 87-94.

Presedo Velo, F. (1982): La Necrópolis de Baza. Excavaciones Arqueológicas en España 119, Ministerio de Cultura, Madrid.

Ridgway, B. S. (1990): Metal Attachments in Greek Marble Sculpture. Marble. Art, Historical and Scientific Perspectives on Ancient Sculptures (M. True y J. Podany, eds.), J. Paul Getty Museum, Los Angeles: $185-206$.

Rolley, C. (1994): La Sculpture Grecque. 1. Des origines au milieu du V siècle. Picard, Paris.

Rouillard, P. (1998): Toro (denominado “torito") de Porcuna. Los Iberos, Príncipes de Occidente. Ministerio de Educación y Cultura, Fundación La Caixa, Barcelona: 237.

Rovira Lloréns, S. (1995): De metalurgia tartésica. Tartessos, 25 años después (1968-1993). Actas del Congreso Conmemorativo del V Symposium Internacional de Prehistoria Peninsular, Ayuntamiento de Jerez de la Frontera: 475-506.

Rovira Lloréns, S. (2008): Aspectos metalúrgicos del yacimiento orientalizante de Medellín. La necrópolis de Medellín III. Estudios analíticos. IV. Interpretación de la necrópolis. V. El marco histórico de Medellín-Conisturgis (M. Almagro-Gorbea, dir.), Bibliotheca Archaeologica Hispana 26-3, Real Academia de la Historia, Madrid: 847-852.

Ruiz, A. y SÁnchez, A. (2003): La cultura de los espacios y los animales entre los príncipes iberos del sur. Arqueología e Iconografia: indagar en las imágenes (T. Tortosa y J.A. Santos, eds.). L'Erma di Bretschneider, Roma: 137-154.

Sanmartí Greco, E. (1987): Notas acerca de un bóvido ibérico en piedra del Museo Arqueológico de Barcelona. Archivo de Prehistoria Levantina, XVII (1): 261-274. 
SchÄFER, T. (1996): Gepickt und versteckt -Zur Bedeutung und Funktion aufgerauhter Oberflächen in der spätarchaischen und frühklassischen Plastik. Jahrbuch des Deutschen Archäologischen Instituts, 111: 25-74.

Torrecillas González, J. F. (1985): La necrópolis de época tartésica del 'Cerrillo Blanco’ (Porcuna, Jaén). Diputación Provincial, Jaén .

Ulreich, H.; Negrete, M. A.; Puch, E.; Perdigones, L. (1990): Die Ausgrabungen 1989 im Schuttang der Phönizischen Ansiedlung an der Guadarranque-Mündung. Madrider Mitteilungen, 31: 194-250.

Vaquerizo Gil, D. (1999): La Cultura Ibérica en Córdoba. Un ensayo de síntesis. Cajasur, Universidad de Córdoba, Córdoba. 